\title{
WestVirginiaUniversity
}

THE RESEARCH REPOSITORY @ WVU

Graduate Theses, Dissertations, and Problem Reports

2006

\section{Development of an animal model of choice between aversive events}

James W. Diller

West Virginia University

Follow this and additional works at: https://researchrepository.wvu.edu/etd

\section{Recommended Citation}

Diller, James W., "Development of an animal model of choice between aversive events" (2006). Graduate Theses, Dissertations, and Problem Reports. 2387.

https://researchrepository.wvu.edu/etd/2387

This Thesis is protected by copyright and/or related rights. It has been brought to you by the The Research Repository @ WVU with permission from the rights-holder(s). You are free to use this Thesis in any way that is permitted by the copyright and related rights legislation that applies to your use. For other uses you must obtain permission from the rights-holder(s) directly, unless additional rights are indicated by a Creative Commons license in the record and/ or on the work itself. This Thesis has been accepted for inclusion in WVU Graduate Theses, Dissertations, and Problem Reports collection by an authorized administrator of The Research Repository @ WVU. For more information, please contact researchrepository@mail.wvu.edu. 
Development of an Animal Model of Choice between Aversive Events James W. Diller

Thesis submitted to the Eberly College of Arts and Sciences at West Virginia University in Partial Fulfillment of the Requirements for the Degree of

\author{
Master of Science
}

in

Psychology

\author{
Karen G. Anderson, Ph. D., Chair \\ Kevin Larkin, Ph. D. \\ Michael Perone, Ph. D. \\ Department of Psychology
}

Morgantown, WV

2006

Keywords: choice, aversive events, delay discounting 


\section{ABSTRACT \\ Development of an Animal Model of Choice between Aversive Events}

\section{James W. Diller}

The present study examined variables controlling choice between aversive events using pigeons as subjects. Initially, a titration procedure using variable-interval (VI) schedules of food and shock delivery contingent on keypecking was conducted to determine a moderately aversive shock intensity and duration. Subjects were then presented with a choice between food delivery followed by either a single shock or three shocks in a discrete-trials procedure. The change in context affected the aversiveness of the shock. In the VI condition, shock presentation resulted in $40-60 \%$ decrease in response rates. In the discrete-trials procedure, however, responding was "all-or-none.” Thus, an attempt to redetermine a moderately aversive shock stimulus within the choice context failed. Despite procedural manipulations, no consistent results were obtained such that one shock was selected more often than three shocks. Theoretical issues related to delayed punishment, discrimination, and conditioned reinforcement, as well as future research directions, are discussed. 


\section{Acknowledgements}

First, I would like to thank Karen Anderson for her support of this thesis; her gung-ho attitude, patience, and advice made this project a valuable learning experience. Thanks, also, to Mike Perone and Kevin Larkin for serving on my committee and allowing me to try this out (despite warnings that it would be difficult).

I would like to thank my colleagues and friends Mirari Elcoro and Chata Dickson for their generosity of support, conversation, and inspiration as throughout the process. I would like to thank my first lab-mates, Jonathan Slezak and Natalie Bruner, for conversation about shocking issues and for restraining birds for me.

Also, I would like to thank K. Andy Lattal and B. Kent Parker for their pigeon-shocking know-how and guidance.

Finally, I would like to thank Laura for support and encouragement throughout this entire process. 


\section{Table of Contents}

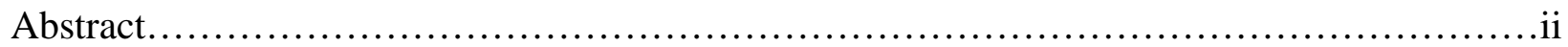

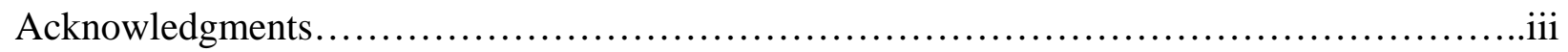

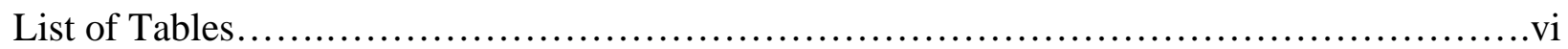

List of Figures.....................................................................

Development of an Animal Model of Choice between Aversive Events........................1

Literature Review................................................................2

Statement of the Problem...............................................................

Method...........................................................................

Subjects..............................................................

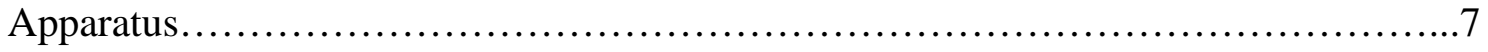

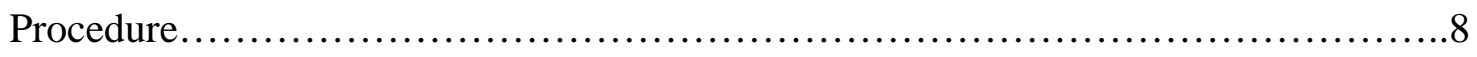

Initial training........................................................

Shock-delivery procedure.............................................9

Shock titration....................................................9

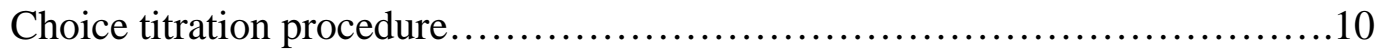

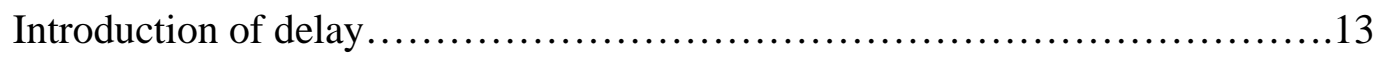

Other procedural changes..............................................13

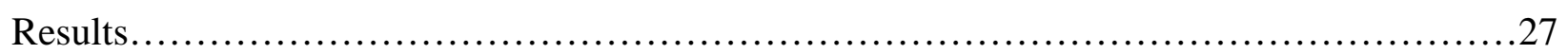

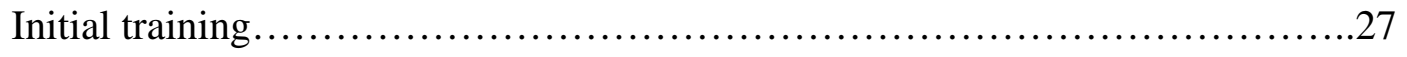

Shock titration......................................................27

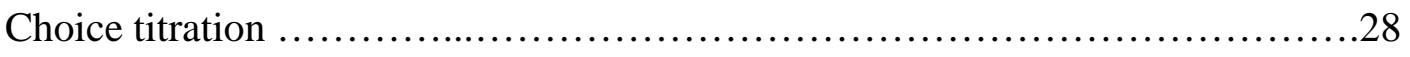

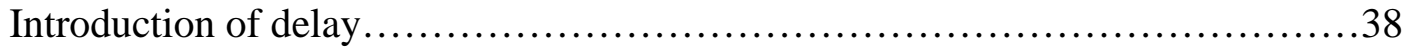


Other procedural changes...............................................47

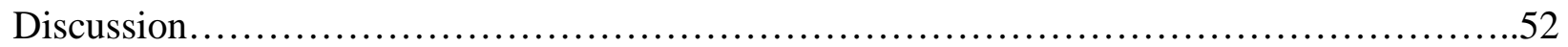

Response-maintenance problems......................................58

Future directions........................................................60

References......................................................................63 
List of Tables.

Table 1: Delays to the presentation of three shocks following food delivery....................14

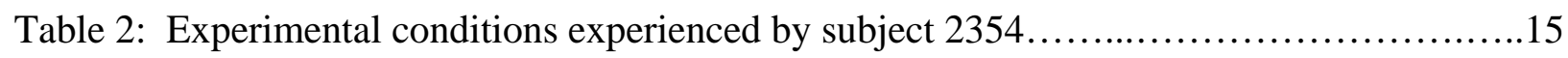

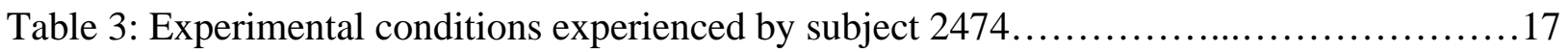

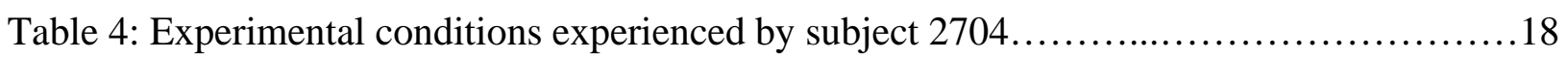

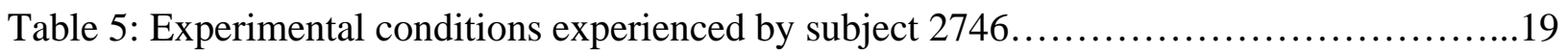

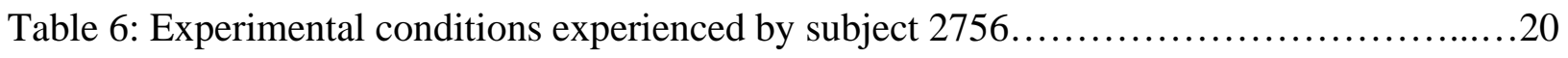

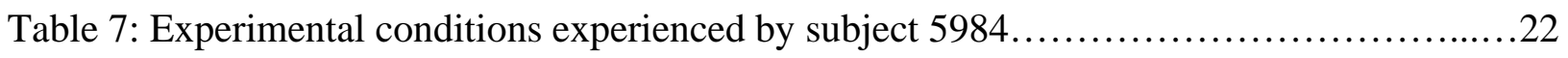

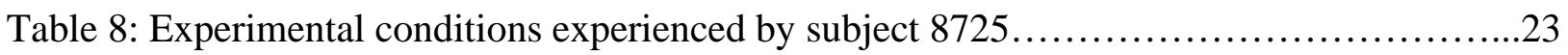

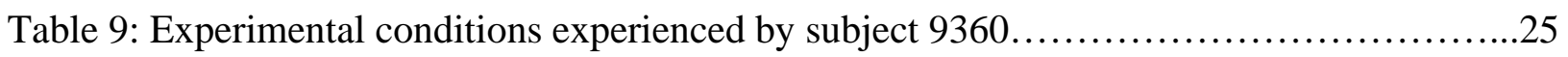




\section{List of Figures}

Figure 1: Responses per minute during the VI-titration phase for subject $2354 \ldots \ldots \ldots \ldots \ldots \ldots . . .29$

Figure 2: Responses per minute during the VI-titration phase for subject $2474 \ldots \ldots \ldots \ldots \ldots \ldots . . . . .30$

Figure 3: Responses per minute during the VI-titration phase for subject $2704 \ldots \ldots \ldots \ldots \ldots \ldots . . . . .31$

Figure 4: Response per minute during the VI-titration phase for subject 2746................32

Figure 5: Responses per minute during the VI-titration phase for subject 2756...............33

Figure 6: Responses per minute during the VI-titration phase for subject $5984 \ldots \ldots \ldots \ldots \ldots \ldots . . . .34$

Figure 7: Responses per minute during the VI-titration phase for subject $8725 \ldots \ldots \ldots \ldots \ldots \ldots . . . .35$

Figure 8: Responses per minute during the VI-titration phase for subject $9360 \ldots \ldots \ldots \ldots \ldots \ldots . . . . .36$

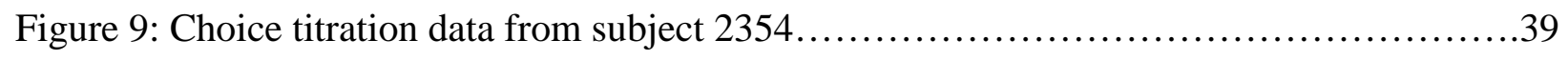

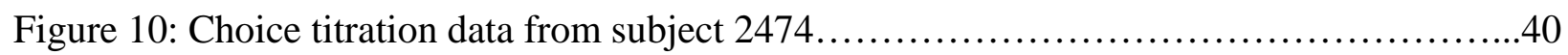

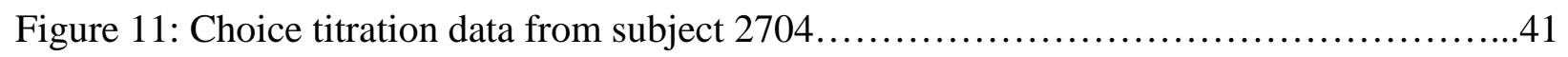

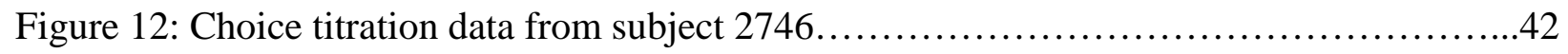

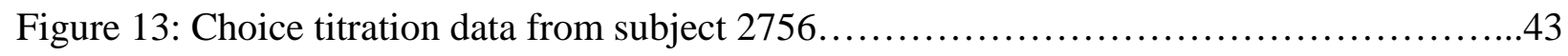

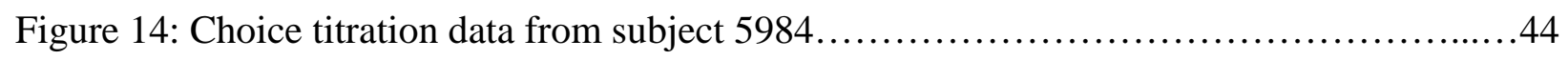

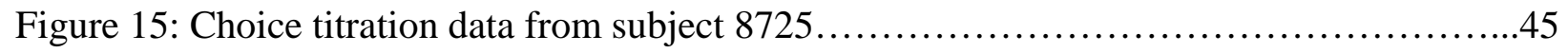

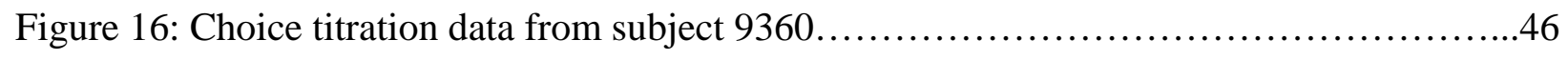

Figure 17: Performance in the choice procedure with delays introduced for subject $2704 \ldots \ldots \ldots .48$

Figure 18: Performance in the choice procedure with delays introduced for subject $8725 \ldots . . . . .49$

Figure 19: Comparison of a single shock or three shocks in the VI-titration procedure...........51 


\section{Development of an Animal Model of Choice between Aversive Events}

Choice has been studied extensively in situations in which an organism must select between two quantitatively different but qualitatively similar positive reinforcers, such as two amounts of money, drugs, or food (see Green \& Myerson, 2004, for a review). Such differential choices can be operationally defined as “self-controlled” or “impulsive” (Ainslie, 1974). Typically, the "self-controlled" choice consists of the selection of a larger reinforcer, which is presented after some delay, to the exclusion of a more immediate, smaller reinforcer. Choice is said to be "impulsive" if the smaller, more immediate reinforcer is chosen to the exclusion of the larger, delayed alternative. When delays are relatively short, the larger reinforcer is often preferred over the smaller reinforcer. However, patterns of responding frequently switch to favor the smaller, more immediate reinforcer as the delay to the larger reinforcer increases. The decrease in responses allocated to the alternative correlated with the large reinforcer as a result of the delay is known as delay discounting (cf. Mazur, 1987). Determinants of impulsive choice/delay discounting have been studied extensively with positive reinforcers. However, little work has been done to extend this area of inquiry into situations where choice is between two different aversive events.

Aversive control has been equated with the terms punishment and negative reinforcement (Skinner, 1953/1965). That is, a stimulus is aversive if its presentation reduces rates of behavior that produced it or if its removal increases rates of behavior that removed it. Given that much behavior is governed by aversive control, the paucity of research in this area of choice is surprising. Outside of the laboratory setting, examples of such choices abound. For example, an individual can choose to have annual physical exams (which may be slightly aversive) or choose to delay going to a physician to the point at which health fails and extensive medical procedures 
are required. People can choose to perform routine car maintenance which may take small investments of time and money, or they can choose to avoid the maintenance, which could possibly result in the need to replace the vehicle entirely. A student can choose to complete an assignment early in the time frame allotted (which could be aversive) or could engage in other behaviors, putting off the work until the night before the assignment is due. In the latter case, the student has potentially compounded the aversive nature of the assignment, adding the additional pressure of the nearing deadline to the already aversive assignment. In these examples and countless others, it is possible to see the relevance of studying the variables that influence choice between an immediate aversive situation and a delayed, more aversive situation.

The present study extends a model of delay discounting to the area of aversive control using pigeons as subjects. Most of the previous body of work in this area has used rats as subjects. The present study will help to elucidate relations between relevant variables in choice situations involving aversive events. Whereas the existing literature with positive reinforcement has involved choice between immediate and delayed positive reinforcers, the present study was designed to examine choice between immediate and delayed aversive consequences.

\section{Literature Review}

Mazur (1987) examined effects of delayed reinforcement and developed a quantitative model of choice that relates magnitude of the reinforcer and delay to the presentation of the reinforcer. This model has been shown to provide a good fit for data obtained from various choice procedures (e.g., Green, Fristoe \& Myerson, 1994; Mazur 1998; Myerson \& Green, 1995). Specifically, Mazur demonstrated that choice for a given reinforcer declines as the delay increases between the response and the delivery of that reinforcer. In Mazur's adjusting-delay procedure, the delay to the large reinforcer was adjusted after each choice trial and the 
indifference point was located. The indifference point was defined as the delay to the large reinforcer at which the small and large reinforcers have equal value, as indicated by $50 \%$ of responses allocated to each alternative. This adjusting-delay procedure can be contrasted with the procedure used by Evenden and Ryan (1996). Evenden and Ryan evaluated multiple pre-set delay values within each experimental session, thereby generating a delay-discounting function in a short time. This method also allows for the interpolation of indifference points.

Specifically, Evenden and Ryan (1996) used a procedure to test effects of drugs (e.g., $d$ amphetamine, diazepam, and imipramine) on delay discounting of food reinforcers. In this experiment, rats were presented with a choice between a single food pellet delivered immediately following a lever press and three food pellets delivered after a longer delay following a lever press. Sessions were organized in blocks of trials in which delays to the large reinforcer (three pellets) progressively increased (between 0.5 and $60 \mathrm{~s}$ ), and the delay to the single food pellet remained constant $(0 \mathrm{~s})$. This procedure has the benefit of generating delay-discounting functions within a single experimental session, allowing for the evaluation of drug effects. The procedure from Evenden and Ryan (1996) served as the basis of the present study, as it provided a means by which delay-discounting functions could be generated within a single session.

An important consideration in this and the previously mentioned studies is that responding (choice) was often maintained by delayed reinforcers. Just as reinforcers have been demonstrated to be effective in maintaining responding after a delay, punishers have been demonstrated to be effective in suppressing responding after a delay (cf. Cairns \& Perkins, 1972). This finding suggests that choice studies can be conducted with delayed punishers that are parallel to those studies conducted with positive reinforcers. 
In a series of experiments, Deluty (1978) extended the self-control and impulsivity choice paradigm to aversive stimuli (e.g., punishers). In a situation of choice between an immediate shock and a longer, delayed shock of the same intensity as the single shock, Deluty operationally defined the selection of a smaller, more immediate shock as the "self-controlled" choice and the choice for the larger, delayed shock as the "impulsive” choice. This designation is similar to the real-life situations described in the introduction of the present paper.

Deluty (1978) used concurrent-chain schedules and manipulated both the duration of shock and the delay to its introduction. In the initial link, rats responded in a two-lever operant chamber on a Random-Interval (RI) 1-min schedule to access the terminal link. In the terminal link, levers retracted, and food pellets were delivered on a random-time (RT) 30-s schedule. The terminal link lasted for one minute. After stability criteria were met, electric shock was introduced during the terminal link. Duration of the shock and delay to its presentation varied between experiments and conditions, but remained correlated with a particular lever (i.e., left or right) within each condition. Shock intensity was held constant at 0.3 milliamps (mA).

Entering the terminal link by responding on one lever resulted in the delivery of a 1-s shock after a delay. Entering the terminal link on the other lever resulted in the delivery of a 2-s shock after a longer delay. Different delay values were tested between conditions such that the delay to the 2-s shock was always 10 s longer than the delay to the 1-s shock. In one of two sequences of shock delays tested, values of delay preceding the 1-s shock were: $2,5,10,20$, and $40 \mathrm{~s}$ and the values of the delays preceding the 2 -s shock were: $12,15,20,30$, and $50 \mathrm{~s}$. In another sequence of shocks, the delay values were doubled for the 2-s shock, relative to the delay values for the 1-s shock. The shock values were paired for the 1-s and 2-s shocks, respectively, as follows: 5 and 10, 10 and 20, 20 and 40, 30 and 60 s. All delay values discussed above were 
used within this experiment. The first delay pair (2 vs. $12 \mathrm{~s}$ ) was in effect for 10 sessions and each consecutive delay pair was in effect for five sessions. The results of this experiment were presented in terms of choice allocation to a particular alternative. When delays were short (e.g., 2 vs. $12 \mathrm{~s}$ and 5 vs. 15 s) more responses were allocated to the initial link leading to the impulsive choice (the 2-s shock) than the self-controlled choice (the 1-s shock). When delays increased (greater than a 10-s delay to the 1-s shock) choice reversed, favoring the self-controlled alternative.

In another experiment within the same series, Deluty (1978) presented the subjects with a choice between a single, 0.5 -s shock delayed by $10 \mathrm{~s}$ and a single shock of varying durations (1.0 to 3.5 s) delayed by 40 s. Again, this choice was within the context of concurrent-chain schedules, as described above. The initial conditions (a choice between a 0.5-s shock vs. 2.0-s shock) were in effect for 20 sessions and subsequent conditions were in effect for five sessions each. When the choice was between a 0.5 -s shock delayed by $10 \mathrm{~s}$ and a 2.0 -s shock delayed by $40 \mathrm{~s}$, responding was allocated equally to each alternative. As the duration of the 40-s delayed shock increased, the responding maintained on the correlated lever decreased and more responses were allocated to the alternative correlated with the 0.5 -s shock delayed by $10 \mathrm{~s}$. When the duration of the shock delayed by $40 \mathrm{~s}$ was less than $2.0 \mathrm{~s}$, subjects responded on this alternative more than when duration was longer than $2.0 \mathrm{~s}$. That is, fewer responses were emitted on the "impulsive" option and more responses were emitted on the "self-controlled" alternative when the "impulsive” shock duration was greater than 2.0 s. Deluty's findings suggest that there is an interaction between the duration of a punisher and its delay to presentation and support the development of an analogue to the delay-discounting paradigm in the area of aversive control. 
Taken together, Deluty's (1978) experiments suggest that it is possible to affect choice by adjusting shock duration and delay.

In an alternative version of Deluty's paradigm of self-control and impulsivity, Bertilson and Dengerink (1975) investigated human subjects' choice between a longer, immediate shock, and a shorter, delayed shock. Preference for immediate shock increased when: (1) subjects were required to make a response that resulted in immediate shock (as opposed to waiting passively for the delayed shock to occur), (2) the absolute duration of the delayed shock was decreased, (3) the subjects had previous experimental experience with shock, and (4) the immediate shock became a less probable outcome. It is interesting to note that the immediate shock, which was longer in duration, was preferred over a shock of shorter duration that followed a delay. The results from this study raise interesting questions about the aversiveness of the signaled temporal gap between when choice is emitted and the punisher is delivered. These data, when taken in conjunction with Deluty's findings, support the notion that effects of changes in delay and magnitude of an aversive stimulus are powerful determinants of choice.

\section{Statement of the Problem}

There is a growing body of literature with delay discounting and positive reinforcement, but there has been relatively little work examining the variables determining choice governed by aversive events (e.g., punishment). Expansion of this body of research would provide a valuable counterpart to the research conducted with positive reinforcement. Such work could illuminate the role of delay in choice between two aversive stimuli of varying magnitudes and temporal distances. The present study was designed to extend previous findings with a standard operant preparation (Evenden \& Ryan, 1996) in a novel context (i.e., a choice between two different punishers). In addition, the current experiment extended Deluty's work by using a different 
procedure (i.e., discrete trial rather than concurrent chains), different delay values, and different subjects (i.e., pigeons instead of rats). The establishment of reliable choice governed by differential aversive events in an additional species would extend the generality of previous findings. This extension could lead to the development of further lines of inquiry.

Method

Subjects

Eight male White Carneau pigeons with previous experimental experience were maintained at approximately $80 \%$ of their ad-libitum weight. They were housed individually with free access to water and grit in their home cages. Temperature, humidity, and illumination (12-hour light-dark cycle) were controlled and maintained at constant values. All subjects were cared for in accordance with guidelines put forth by West Virginia University’s Animal Care and Use Committee.

Apparatus

Four operant chambers located in sound-attenuating enclosures were used in this experiment. Closed circuit cameras were affixed to the operant chamber such that activity within the operant chamber could be observed using a video monitor. Each chamber measured 305 mm wide by $335 \mathrm{~mm}$ deep, and was $375 \mathrm{~mm}$ tall. An aluminum panel comprised the front wall of the chambers. Three translucent plastic keys, $25 \mathrm{~mm}$ in diameter, were located on the aluminum panel, $265 \mathrm{~mm}$ from the chamber floor. The centers of the keys were $90 \mathrm{~mm}$ apart, and the leftmost key was $70 \mathrm{~mm}$ from the left edge of the chamber. Each key could be transluminated by four or five 28-V miniature lamps that could be covered by colored lens caps. Food delivery (mixed grain) was provided by a food hopper which was raised into a 65- by 55-mm opening in the front panel of the chamber. The bottom edge of the opening was located $180 \mathrm{~mm}$ below the 
center of the center key. A white lamp above the food hopper was illuminated when grain was presented. A ventilation fan circulated air and masked extraneous noise throughout the duration of the experimental session. Shock was administered from a shock generator (MED Associates ENV 410), and all experimental events were controlled by a computer running MedPC software. Programs were written by the author using MedState notation. The computer, shock generator, and video monitor were situated in a room adjacent to the room containing the operant chambers.

\section{Procedure}

Initial training. Experimental sessions were conducted Monday through Friday at approximately the same time each day for each group of four subjects. Since the subjects were experienced but had not been involved in research for some period of time, a modified autoshaping program (Brown and Jenkins, 1968) was used as the first phase of the training. Specifically, subjects were placed in the darkened experimental chamber. Ten minutes later, the

center key was illuminated with a white light for $8 \mathrm{~s}$. Following this period of time, the keylight was extinguished, and the hopper was raised for 4 s. After food presentation, the chamber was darkened for an average of 30 seconds (i.e., a variable-time intertrial interval (VT ITI)). When the key was illuminated, a key peck resulted in immediate grain presentation (i.e., a fixed-ratio (FR) 1 schedule was in effect). Each training session lasted until 40 grain presentations had occurred. This training continued until each subject reliably pecked the illuminated key.

After subjects were reliably responding in the autoshaping procedure, a VI 2-s schedule was in effect on the center key. The center key was used in this situation because it would not be used in the choice procedure (see below). Responses on the illuminated key each resulted in 3-s access to grain followed by a VI 30-s ITI. Sessions ended after 30 grain presentations. The mean interval value was gradually increased, across sessions, from 2 to 30 s. The mean response rates 
(key pecks/min) from the final nine sessions were examined in blocks of three. Rates were considered stable when there was no upward or downward trend, and the means did not vary from the overall mean of the nine sessions by more than $20 \%$. This analysis was supplemented by visual inspection of the data. Once stability criteria were met, electrodes were implanted (see below), response-dependent shock was introduced, and titration of shock value began.

Shock-delivery procedure. After stable response rates were observed, a method of implanting nichrome wire electrodes about the pubis bones of pigeons was employed (Azrin, 1959). To facilitate connection to the shock generator and to prevent harm to the subjects caused by pulling on the wires, the implanted electrodes were connected to wires that were attached to a leather vest. The subjects wore the vests for the duration of the experiment. The wires on the vests terminated in 2-prong plugs, and the plugs were attached to a shock generator during the experimental sessions via a plug that extended through an opening in the top of the operant chamber. This plug was attached to a wire that ran through a conduit in the wall and to the shock generator. The electrodes were cleaned regularly to ensure the health of the subjects and consistent, unimpeded flow of the electric current. All connections were inspected prior to each experimental session.

Shock titration. In this portion of training, a two-component multiple schedule was in effect for pecks on the center key. Each session was divided into five segments. The first, third, and fifth component each lasted 6 min. In these components, an amber light correlated with a VI30 s schedule resulting in 3-s access to mixed grain was presented, followed by a VT ITI (averaging $30 \mathrm{~s}$ ). In the second and fourth components (which lasted for 9 min each), a red keylight was correlated with VI-30 s schedule. Following completion of the response requirement, $3 \mathrm{~s}$ of access to mixed grain was followed immediately by a 500 millisecond (ms) 
shock. Shock intensity values were adjusted across sessions, beginning with $0 \mathrm{~mA}$, and increasing by $0.5 \mathrm{~mA}$ increments across sessions such that shock intensity was titrated to a value that resulted in an average of a 40 to $60 \%$ decrease in response rate. To determine if this suppression had occurred, the mean response rate in components 2 and 4 were compared to the mean response rate in components 1,3 , and 5 . This phase of the experiment continued until responding in the food-shock condition was suppressed to approximately $50 \%$ of the responding in the food-only condition for at least nine consecutive sessions and stability was determined. Behavior was considered stable when there were no increasing or decreasing trends and no more than $20 \%$ variability between the means of the last nine sessions (compared in three blocks of three sessions each). The minimum shock intensity required to suppress key pecking was used in the next phase of the experimental design. A shock duration of 500 ms was initially used. If complete suppression of the keypeck response was observed, shock duration was decreased to 200 ms. The VI-VI titration procedure was successful for four subjects, who were then advanced to the choice procedure. When in the choice procedure, however, these subjects failed to respond, and it became necessary to reassess the shock intensity within the choice procedure. At this point, all subjects were advanced to the choice titration procedure.

Choice titration procedure. Sessions began with a 10-min period in which the only activated stimulus was the ventilation fan. As in the procedure used by Evenden and Ryan (1996), sessions were divided into five blocks of two forced-choice trials and six free-choice trials each. Forced-choice trials always came first within the block of trials and provided exposure to the different contingencies. In forced-choice trials, the houselight and one side key (randomly determined by the computer) were illuminated. A peck on an illuminated key led to one of two consequences. For example, a response on the left key turned off the houselight and 
led immediately to 3-s access to mixed grain in the food hopper. Immediately after food presentation ended, a single shock (of an intensity and duration individually determined for each subject, as described above), accompanied by a flash of the houselight, was administered. Following shock delivery, the houselight was extinguished for the duration of the ITI. The ITI lasted for $100 \mathrm{~s}$ minus food delivery time and the latency to the first response to ensure that choosing the single, immediate shock did not lead to the next successive trial more quickly than the choosing the multiple, delayed shocks. After the ITI, the second forced-choice trial began with the illumination of the appropriate stimuli.

In the present example, a response to the right key resulted in the keylight turning off and $3 \mathrm{~s}$ of food presentation. Three shocks were then delivered, accompanied by flashing of the houselight. The shocks were delivered at intervals equal to the duration of the shock. For example, following the food delivery, the shock would be turned on for $0.5 \mathrm{~s}$, off for $0.5 \mathrm{~s}$, on for $0.5 \mathrm{~s}$, off for $0.5 \mathrm{~s}$, on for $0.5 \mathrm{~s}$ and then off for the rest of the trial. All stimuli were extinguished immediately after the delivery of the third shock and remained off until the ITI terminated and the next choice trial began.

After two forced-choice trials, the first of six free-choice trials began. In free-choice trials, the houselight and both side keys were illuminated, and pecks on either key led to programmed consequences. Subjects were allowed to choose between the two consequences associated with the two keys during free-choice trials. At the end of the sixth free-choice trial, the block of trials was over. The next block of trials began with two new forced-choice trials. For the titration procedure, the delay to the three shocks was held constant at $0 \mathrm{~s}$ in all blocks of trials. That is, the choice presented to the subjects was a single shock or three shocks delivered 
immediately following food presentation. Experimental sessions ended with the completion of the fifth block of trials.

If subjects did not peck an illuminated key within the first $30 \mathrm{~s}$ of each trial, the keylight was extinguished. Three shocks were then delivered and the ITI began. There was no opportunity to receive food in the remainder of the trial in which responding did not occur before the expiration of the limited hold. For the trials in which no response occurred (i.e., omitted trials), the ITI was the same as in the previous trials (100 s less the initial $30 \mathrm{~s}$ and the length of the delay before the shocks). If the subject did not respond in five consecutive trials, the experimental session was terminated. If sessions regularly terminated prematurely (due to omissions), attempts were made to reinstate responding through response-independent presentation of food and/or decreasing shock intensity in the subsequent session.

Shock intensity was adjusted between sessions until subjects chose the single shock in more than 20 free-choice trials for a minimum of three consecutive sessions. After this occurred, the sides correlated with the single- or three-shock alternatives were reversed (e.g., if three-shock contingency was correlated with the left key initially, it became available on the right key). If response patterns reversed and subjects chose the three shocks in ten or fewer free-choice trials, delays were introduced prior to the delivery of the three shocks. Only two subjects (2704 and 8725) met this criterion and were presented with delays between the delivery of food and the delivery of shock.

If behavior failed to meet the criterion to advance to the delayed-shock conditions, shock intensity was adjusted for the next subsequent session. Following an extended period of failure to maintain more response allocation on the key correlated with the single shock, procedural changes (as described below) were made. 
Introduction of delay. For two subjects whose behavior satisfied the criteria stated above, delays were introduced between food presentation and the delivery of the three shocks. Following a response on the illuminated key and food presentation, the keylight was extinguished, and the houselight was illuminated for the duration of the delay. After the programmed delay elapsed, three shocks were delivered and the next trial began $100 \mathrm{~s}$ after the onset of the previous trial, as in the choice titration procedure described above. The single shock continued to occur immediately after the food presentation. Delay values were changed within experimental sessions, increasing across blocks of eight trials (two forced-choice trials and six free-choice trials). Prior to reaching the terminal delay values, delays increased between sessions, beginning with sessions with only 0-s delays (i.e. the choice between one immediate shock and three immediate shocks was presented throughout the entire sessions). Delay sequences are presented in Table 1, and were strictly increasing, both within and between sessions. Consequences for pecking each key continued to be associated with the same key location as in previous conditions.

Other procedural changes. The following manipulations were conducted based on the behavior of individual subjects. The conditions experienced by each subject are presented in Tables 2 through 9. If key pecking persisted for the three-shock alternative, food delivery was terminated following responses on the key correlated with the delivery of the three shocks; shock delivery continued as in other choice-titration sessions. This contingency remained in effect until more pecking was allocated to the key correlated than the single shock than was allocated to the key correlated with the single shock. Specifically, fewer than 10 free-choice responses could 
Table 1

Sequential delays to the presentation of three shocks following food delivery. Most sessions conducted consisted of all 0-s delays (i.e., a choice between one shock now and three shocks now), as in the first row.

\begin{tabular}{ccccc}
\hline Block 1 & Block 2 & Block 3 & Block 4 & Block 5 \\
\hline $0 \mathrm{~s}$ & $0 \mathrm{~s}$ & $0 \mathrm{~s}$ & $0 \mathrm{~s}$ & $0 \mathrm{~s}$ \\
$0 \mathrm{~s}$ & $1 \mathrm{~s}$ & $2 \mathrm{~s}$ & $4 \mathrm{~s}$ & $6 \mathrm{~s}$ \\
$0 \mathrm{~s}$ & $2 \mathrm{~s}$ & $4 \mathrm{~s}$ & $8 \mathrm{~s}$ & $16 \mathrm{~s}$ \\
$0 \mathrm{~s}$ & $5 \mathrm{~s}$ & $10 \mathrm{~s}$ & $20 \mathrm{~s}$ & $40 \mathrm{~s}$ \\
$0 \mathrm{~s}$ & $10 \mathrm{~s}$ & $20 \mathrm{~s}$ & $40 \mathrm{~s}$ & $60 \mathrm{~s}$ \\
\hline
\end{tabular}


Table 2.

Experimental conditions experienced by subject 2354. The subject number is given in the upper left corner of the table. The column labels and information correspond as follows: The column under the subject number is used for special notations. $\neq$ indicates that the shock generator was set incorrectly for this session. P in the first column indicates that the houselight was extinguished when the food hopper was raised during this condition. The "Side" column indicates which side key is correlated with the three shocks. "Delay" indicates the highest delay value preceding the three shocks. "Duration" indicates the duration of the shocks, in seconds. "Sig" indicates if the houselight flash accompanies shock delivery; a "no" in this column indicates there was no houselight flash accompanying the shock delivery. An asterisk in the EXT column indicates that no food was presented following a response on the key correlated with the three shocks. The number in the " $m A$ " column indicates the intensity of the shocks delivered, in $m A$. The "Sess" column indicates the number of sessions these conditions were in effect.

Numbers in the "Omit" column indicate the number of times the session was terminated due to omissions after five consecutive trials. Values in the "Equip" column indicate that the subject became disconnected from the shock generator, unplugged, or wires broke during the experimental session.

\begin{tabular}{|c|c|c|c|c|c|c|c|c|c|}
\hline 2354 & Side & Delay & Duration (s) & Sig & EXT & $\mathrm{mA}$ & Sess & Omit & Equip \\
\hline & $\mathrm{L}$ & 0 & 0.2 & No & & 0 & 2 & 0 & 0 \\
\hline & L & 0 & 0.2 & No & & 2 & 4 & 2 & 0 \\
\hline & L & 0 & 0.2 & No & & 0 & 3 & 0 & 0 \\
\hline & L & 0 & 0.2 & No & & 2 & 3 & 0 & 0 \\
\hline & L & 0 & 0.2 & No & & 2.5 & 1 & 1 & 0 \\
\hline & L & 0 & 0.2 & No & & 0 & 2 & 1 & 0 \\
\hline & L & 0 & 0.2 & No & & 1 & 4 & 0 & 0 \\
\hline & L & 0 & 0.2 & No & & 1.5 & 2 & 1 & 0 \\
\hline
\end{tabular}


Table 2, Continued.

\begin{tabular}{|c|c|c|c|c|c|c|c|c|c|}
\hline 2354 & Side & Delay & Duration (s) & Sig & EXT & $\mathrm{mA}$ & Sess & Omit & Equip \\
\hline & $\mathrm{L}$ & 0 & 0.2 & No & & 0 & 1 & 0 & 0 \\
\hline & L & 0 & 0.2 & No & & 1.5 & 5 & 0 & 0 \\
\hline \multirow[t]{12}{*}{$\neq$} & L & 0 & 0.2 & No & & $4.5^{\star}$ & 1 & 1 & 0 \\
\hline & L & 0 & 0.2 & No & & 1 & 18 & 0 & 0 \\
\hline & $\mathrm{R}$ & 0 & 0.2 & Yes & & 1 & 11 & 0 & 0 \\
\hline & $\mathrm{R}$ & 0 & 0.2 & Yes & * & 1 & 7 & 0 & 0 \\
\hline & $\mathrm{R}$ & 0 & 0.2 & Yes & & 1 & 9 & 0 & 1 \\
\hline & L & 0 & 0.2 & Yes & & 1 & 15 & 0 & 0 \\
\hline & L & 0 & 0.2 & Yes & & 1.5 & 4 & 0 & 0 \\
\hline & L & 0 & 0.2 & Yes & & 2 & 12 & 6 & 0 \\
\hline & L & 0 & 0.2 & Yes & & 1.5 & 12 & 4 & 0 \\
\hline & $\mathrm{R}$ & 0 & 0.2 & Yes & & 1.5 & 14 & 0 & 0 \\
\hline & $\mathrm{R}$ & 0 & 0.2 & Yes & * & 2 & 9 & 0 & 0 \\
\hline & $\mathrm{R}$ & 0 & 0.2 & Yes & & 2 & 14 & 4 & 1 \\
\hline$P$ & $\mathrm{R}$ & 0 & 0.2 & Yes & & 2 & 22 & 13 & 0 \\
\hline$p$ & $\mathrm{~L}$ & 0 & 0.2 & Yes & & 2 & 20 & 17 & 0 \\
\hline
\end{tabular}


Table 3.

Experimental conditions experienced by subject 2474. See the caption for Table 2 for a description of the data contained within the table.

\begin{tabular}{|c|c|c|c|c|c|c|c|c|c|}
\hline 2474 & Side & Delay & Duration (s) & Sig & EXT & $\mathrm{mA}$ & Sess & Omit & Equip \\
\hline & $\mathrm{L}$ & 0 & 0.2 & No & & 0 & 3 & 0 & 0 \\
\hline & L & 0 & 0.2 & No & & 2 & 1 & 1 & 0 \\
\hline & L & 0 & 0.2 & No & & 0 & 9 & 1 & 0 \\
\hline & L & 0 & 0.2 & No & & 1 & 4 & 2 & 0 \\
\hline & L & 0 & 0.2 & No & & 0 & 3 & 1 & 0 \\
\hline & L & 0 & 0.2 & No & & 1 & 8 & 1 & 1 \\
\hline & L & 0 & 0.2 & Yes & & 1 & 9 & 1 & 1 \\
\hline & L & 0 & 0.2 & Yes & & 1.5 & 22 & 6 & 1 \\
\hline & L & 0 & 0.2 & Yes & & 1.5 & 5 & 2 & 1 \\
\hline & $R$ & 0 & 0.2 & Yes & * & 1.5 & 13 & 7 & 1 \\
\hline & $R$ & 0 & 0.2 & Yes & & 1.5 & 8 & 4 & 0 \\
\hline & $R$ & 0 & 0.2 & Yes & & 1.5 & 10 & 1 & 0 \\
\hline & $\mathrm{R}$ & 0 & 0.2 & Yes & & 2 & 5 & 3 & 0 \\
\hline & $R$ & 0 & 0.2 & Yes & & 1.5 & 23 & 9 & 0 \\
\hline & $\mathrm{R}$ & 0 & 0.2 & Yes & * & 1.5 & 9 & 3 & 0 \\
\hline & $R$ & 0 & 0.2 & Yes & & 1.5 & 9 & 3 & 0 \\
\hline & $R$ & 0 & 0.2 & Yes & & 1.5 & 19 & 3 & 0 \\
\hline p & $R$ & 0 & 0.2 & Yes & & 1.5 & 7 & 2 & 0 \\
\hline p & $R$ & 0 & 0.2 & Yes & & 2 & 32 & 18 & 0 \\
\hline
\end{tabular}


Table 4.

Experimental conditions experienced by subject 2704. See the caption for Table 2 for a description of the data contained within the table.

\begin{tabular}{|c|c|c|c|c|c|c|c|c|c|}
\hline 2704 & Side & Delay & Duration (s) & Sig & EXT & $\mathrm{mA}$ & Sess & Omit & Equip \\
\hline & $\bar{L}$ & 6 & 0.2 & No & & 0 & 1 & 0 & 0 \\
\hline & L & 6 & 0.2 & No & & 3.5 & 3 & 2 & 0 \\
\hline & L & 6 & 0.2 & No & & 0 & 4 & 0 & 0 \\
\hline & L & 6 & 0.2 & No & & 2 & 3 & 0 & 0 \\
\hline & L & 6 & 0.2 & No & & 2.5 & 1 & 0 & 0 \\
\hline & L & 0 & 0.2 & No & & 2.5 & 7 & 3 & 1 \\
\hline & L & 0 & 0.2 & No & & 3 & 4 & 0 & 0 \\
\hline & L & 0 & 0.2 & No & & 3.5 & 7 & 2 & 1 \\
\hline & L & 0 & 0.2 & No & & 2 & 3 & 0 & 0 \\
\hline & L & 0 & 0.2 & No & & 2.5 & 7 & 2 & 0 \\
\hline & L & 0 & 0.2 & Yes & & 1 & 3 & 0 & 0 \\
\hline & L & 0 & 0.2 & Yes & & 2 & 10 & 0 & 0 \\
\hline & L & 0 & 0.2 & Yes & & 2.5 & 2 & 0 & 0 \\
\hline & L & 0 & 0.2 & Yes & & 2 & 14 & 5 & 1 \\
\hline & $\mathrm{L}$ & 0 & 0.2 & Yes & & 1 & 6 & 2 & 0 \\
\hline & L & 0 & 0.2 & Yes & & 2 & 3 & 1 & 0 \\
\hline & L & 0 & 0.2 & Yes & * & 2 & 10 & 2 & 2 \\
\hline & L & 0 & 0.2 & Yes & & 2 & 8 & 0 & 0 \\
\hline & $R$ & 0 & 0.2 & Yes & & 2 & 22 & 1 & 1 \\
\hline & $R$ & 16 & 0.2 & Yes & & 2 & 11 & 0 & 0 \\
\hline & $\mathrm{R}$ & 40 & 0.2 & Yes & & 2 & 10 & 0 & 0 \\
\hline & $\mathrm{R}$ & 60 & 0.2 & Yes & & 2 & 5 & 0 & 1 \\
\hline & $R$ & 0 & 0.2 & Yes & & 2 & 15 & 0 & 1 \\
\hline P & $\mathrm{R}$ & 0 & 0.2 & Yes & & 2 & 1 & 0 & 0 \\
\hline p & $\mathrm{R}$ & 0 & 0.2 & Yes & & 2.5 & 11 & 0 & 0 \\
\hline p & $\mathrm{R}$ & 0 & 0.2 & Yes & & 3 & 5 & 1 & 0 \\
\hline
\end{tabular}


Table 5.

Experimental conditions experienced by subject 2746. See the caption for Table 2 for a description of the data contained within the table.

\begin{tabular}{|c|c|c|c|c|c|c|c|c|c|}
\hline 2746 & Side & Delay & Duration (s) & Sig & EXT & $\mathrm{mA}$ & Sess & Omit & Equip \\
\hline & $R$ & 0 & 0.2 & No & & 0 & 3 & 0 & 1 \\
\hline & $R$ & 0 & 0.2 & No & & 2 & 3 & 2 & 0 \\
\hline & $R$ & 0 & 0.2 & No & & 0 & 3 & 0 & 0 \\
\hline & $R$ & 0 & 0.2 & No & & 2 & 5 & 0 & 1 \\
\hline & L & 0 & 0.2 & No & & 2 & 1 & 1 & 0 \\
\hline & L & 0 & 0.2 & No & & 0 & 1 & 0 & 0 \\
\hline & L & 0 & 0.2 & No & & 1 & 1 & 0 & 0 \\
\hline & L & 0 & 0.2 & No & & 1.5 & 4 & 0 & 1 \\
\hline & L & 0 & 0.2 & No & & 2 & 2 & 1 & 0 \\
\hline & L & 0 & 0.2 & Yes & & 2 & 10 & 0 & 2 \\
\hline & L & 0 & 0.2 & Yes & & 2.5 & 2 & 2 & 0 \\
\hline & L & 0 & 0.2 & Yes & & 2 & 10 & 7 & 1 \\
\hline & L & 0 & 0.2 & Yes & & 1 & 8 & 0 & 2 \\
\hline & L & 0 & 0.2 & Yes & & 1.5 & 18 & 0 & 5 \\
\hline & L & 0 & 0.2 & Yes & & 2 & 12 & 0 & 0 \\
\hline & L & 0 & 0.2 & Yes & & 2.5 & 5 & 0 & 0 \\
\hline & L & 0 & 0.2 & Yes & & 3 & 6 & 5 & 0 \\
\hline & L & 0 & 0.2 & Yes & & 2.5 & 2 & 2 & 0 \\
\hline & L & 0 & 0.2 & Yes & & 2 & 22 & 2 & 1 \\
\hline & L & 0 & 0.2 & Yes & * & 2 & 5 & 0 & 0 \\
\hline & L & 0 & 0.2 & Yes & & 2 & 13 & 1 & 0 \\
\hline & L & 0 & 0.2 & Yes & * & 2 & 6 & 0 & 0 \\
\hline & L & 0 & 0.2 & Yes & & 2.5 & 4 & 1 & 0 \\
\hline & $R$ & 0 & 0.2 & Yes & & 2.5 & 3 & 0 & 0 \\
\hline
\end{tabular}


Table 6.

Experimental conditions experienced by subject 2756. See the caption for Table 2 for a description of the data contained within the table.

\begin{tabular}{|c|c|c|c|c|c|c|c|c|c|}
\hline 2756 & Side & Delay & Duration (s) & Sig & EXT & $\mathrm{mA}$ & Sess & Omit & Equip \\
\hline & $R$ & 6 & 0.2 & No & & 0 & 3 & 0 & 0 \\
\hline & $\mathrm{R}$ & 6 & 0.2 & No & & 0.5 & 1 & 0 & 0 \\
\hline & $\mathrm{R}$ & 6 & 0.2 & No & & 1 & 1 & 0 & 0 \\
\hline & $\mathrm{R}$ & 6 & 0.2 & No & & 1.5 & 1 & 0 & 0 \\
\hline & $\mathrm{R}$ & 6 & 0.2 & No & & 2 & 1 & 0 & 0 \\
\hline & $\mathrm{R}$ & 6 & 0.2 & No & & 2.5 & 1 & 0 & 0 \\
\hline & $R$ & 6 & 0.2 & No & & 3 & 1 & 0 & 0 \\
\hline & $\mathrm{R}$ & 6 & 0.2 & No & & 3.5 & 1 & 0 & 0 \\
\hline & $R$ & 6 & 0.2 & No & & 0 & 1 & 0 & 0 \\
\hline & $R$ & 6 & 0.2 & No & & 4 & 1 & 0 & 0 \\
\hline & $\mathrm{R}$ & 6 & 0.2 & No & & 4.5 & 1 & 1 & 0 \\
\hline & $R$ & 6 & 0.2 & No & & 5 & 1 & 0 & 0 \\
\hline & $R$ & 6 & 0.2 & No & & 5.5 & 1 & 0 & 0 \\
\hline & $\mathrm{R}$ & 6 & 0.2 & No & & 4.5 & 1 & 0 & 0 \\
\hline & $R$ & 6 & 0.2 & No & & 5 & 2 & 0 & 0 \\
\hline & $\mathrm{R}$ & 6 & 0.2 & No & & 5.5 & 12 & 0 & 0 \\
\hline & $\mathrm{R}$ & 0 & 0.2 & No & & 5.5 & 1 & 0 & 0 \\
\hline & L & 0 & 0.2 & No & & 5.5 & 1 & 0 & 0 \\
\hline & $\mathrm{R}$ & 0 & 0.2 & No & * & 5.5 & 1 & 0 & 0 \\
\hline & $\mathrm{R}$ & 0 & 0.2 & No & & 5.5 & 2 & 1 & 0 \\
\hline & $R$ & 0 & 0.2 & No & & 0 & 1 & 0 & 0 \\
\hline & $\mathrm{R}$ & 0 & 0.2 & No & & 5.5 & 1 & 0 & 0 \\
\hline & $R$ & 6 & 0.2 & No & & 5.5 & 1 & 0 & 0 \\
\hline & $R$ & 16 & 0.2 & No & & 5.5 & 1 & 1 & 0 \\
\hline & $\mathrm{R}$ & 6 & 0.2 & No & & 0 & 2 & 0 & 0 \\
\hline & $\mathrm{R}$ & 6 & 0.2 & No & & 2 & 1 & 0 & 0 \\
\hline & $R$ & 6 & 0.5 & No & & 2 & 2 & 0 & 0 \\
\hline & $\mathrm{R}$ & 0 & 0.5 & No & & 2 & 4 & 1 & 0 \\
\hline & $R$ & 0 & 0.5 & No & & 2.5 & 3 & 0 & 0 \\
\hline & $\mathrm{R}$ & 0 & 0.5 & No & & 3 & 6 & 0 & 0 \\
\hline
\end{tabular}


Table 6, Continued.

\begin{tabular}{|c|c|c|c|c|c|c|c|c|c|}
\hline 2756 & Side & Delay & Duration (s) & Sig & EXT & $\mathrm{mA}$ & Sess & Omit & Equip \\
\hline & $\mathrm{R}$ & 0 & 0.5 & No & & 3.5 & 2 & 0 & 0 \\
\hline & $\mathrm{R}$ & 0 & 0.5 & No & & 4 & 4 & 0 & 0 \\
\hline & $\mathrm{R}$ & 0 & 0.5 & No & & 4.5 & 2 & 0 & 0 \\
\hline & $\mathrm{R}$ & 0 & 0.5 & No & & 5 & 3 & 0 & 0 \\
\hline & $\mathrm{R}$ & 0 & 0.5 & No & & 5 & 10 & 0 & 0 \\
\hline & $\mathrm{R}$ & 0 & 0.5 & No & & 5 & 15 & 0 & 2 \\
\hline & $\mathrm{R}$ & 0 & 0.5 & Yes & & 5 & 3 & 0 & 0 \\
\hline & $\mathrm{R}$ & 0 & 0.5 & Yes & * & 5 & 4 & 0 & 0 \\
\hline & $\mathrm{R}$ & 0 & 0.5 & Yes & & 5 & 16 & 6 & 2 \\
\hline & $\mathrm{R}$ & 0 & 0.5 & Yes & * & 5 & 10 & 4 & 0 \\
\hline & $\mathrm{R}$ & 0 & 0.5 & Yes & & 5 & 14 & 1 & 1 \\
\hline & $\mathrm{R}$ & 0 & 0.5 & Yes & & 5.5 & 7 & 2 & 0 \\
\hline & $\mathrm{R}$ & 0 & 0.5 & Yes & * & 5 & 14 & 7 & 0 \\
\hline & $\mathrm{R}$ & 0 & 0.5 & Yes & & 5 & 10 & 1 & 1 \\
\hline & $\mathrm{R}$ & 0 & 0.5 & Yes & * & 5 & 5 & 4 & 1 \\
\hline & $\mathrm{R}$ & 0 & 0.5 & Yes & & 5 & 20 & 8 & 0 \\
\hline & $\mathrm{L}$ & 0 & 0.5 & Yes & & 5 & 26 & 8 & 0 \\
\hline
\end{tabular}


Table 7.

Experimental conditions experienced by subject 5984. See the caption for Table 2 for a description of the data contained within the table.

\begin{tabular}{|c|c|c|c|c|c|c|c|c|c|}
\hline 5984 & Side & Delay & Duration (s) & Sig & EXT & $\mathrm{mA}$ & Sess & Omit & Equip \\
\hline & $R$ & 0 & 0.5 & No & & 0 & 1 & 0 & 0 \\
\hline & $\mathrm{R}$ & 0 & 0.5 & No & & 5.5 & 1 & 1 & 0 \\
\hline & $\mathrm{R}$ & 0 & 0.5 & No & & 0 & 2 & 0 & 0 \\
\hline & $R$ & 0 & 0.5 & No & & 5.5 & 2 & 1 & 0 \\
\hline & $R$ & 0 & 0.5 & No & & 0 & 3 & 0 & 0 \\
\hline & $R$ & 0 & 0.5 & No & & 2 & 2 & 0 & 0 \\
\hline & $R$ & 0 & 0.5 & No & & 2 & 4 & 0 & 0 \\
\hline & $\mathrm{R}$ & 0 & 0.5 & No & & 2.5 & 3 & 0 & 0 \\
\hline & $R$ & 0 & 0.5 & No & & 3 & 4 & 0 & 0 \\
\hline & $R$ & 0 & 0.5 & No & & 3.5 & 5 & 0 & 0 \\
\hline & $R$ & 0 & 0.5 & No & & 4 & 1 & 0 & 0 \\
\hline & $R$ & 0 & 0.5 & No & & 4.5 & 1 & 0 & 0 \\
\hline & $\mathrm{R}$ & 0 & 0.5 & No & & 4 & 1 & 0 & 0 \\
\hline & $R$ & 0 & 0.5 & No & & 4.5 & 4 & 0 & 0 \\
\hline & L & 0 & 0.5 & No & & 4.5 & 9 & 0 & 0 \\
\hline & $\mathrm{R}$ & 0 & 0.5 & No & & 4.5 & 9 & 0 & 0 \\
\hline & $R$ & 0 & 0.5 & Yes & & 4.5 & 9 & 0 & 2 \\
\hline & $R$ & 0 & 0.5 & Yes & * & 4.5 & 5 & 0 & 0 \\
\hline & $\mathrm{R}$ & 0 & 0.5 & Yes & & 4.5 & 2 & 0 & 0 \\
\hline & $\mathrm{R}$ & 0 & 0.5 & Yes & * & 4.5 & 3 & 0 & 0 \\
\hline & $R$ & 0 & 0.5 & Yes & & 4.5 & 17 & 0 & 4 \\
\hline & $R$ & 0 & 0.5 & Yes & * & 4.5 & 7 & 0 & 0 \\
\hline & $R$ & 0 & 0.5 & Yes & & 4.5 & 15 & 1 & 0 \\
\hline & $R$ & 0 & 0.5 & Yes & & 5 & 6 & 0 & 5 \\
\hline & $\mathrm{R}$ & 0 & 0.5 & Yes & * & 4.5 & 11 & 0 & 0 \\
\hline & $R$ & 0 & 0.5 & Yes & & 4.5 & 5 & 0 & 0 \\
\hline & $R$ & 0 & 0.5 & Yes & & 4.5 & 7 & 0 & 0 \\
\hline & $R$ & 0 & 0.5 & Yes & & 5 & 11 & 0 & 1 \\
\hline & $\mathrm{R}$ & 0 & 0.5 & Yes & & 5.5 & 14 & 1 & 0 \\
\hline
\end{tabular}


Table 8.

Experimental conditions experienced by subject $8725 .+$ indicates that the order of the food and shock were reversed (i.e., shock was administered immediately after a response and before food presentation). See the caption for Table 2 for a description of the rest of the data contained within the table.

\begin{tabular}{|c|c|c|c|c|c|c|c|c|c|}
\hline 8725 & Side & Delay & Duration (s) & Sig & EXT & $\mathrm{mA}$ & Sess & Omit & Equip \\
\hline & $\mathrm{R}$ & 0 & 0.2 & No & & 0 & 2 & 0 & 0 \\
\hline & $R$ & 0 & 0.2 & No & * & 0 & 3 & 0 & 0 \\
\hline & $R$ & 0 & 0.2 & No & * & 2 & 1 & 0 & 0 \\
\hline & $R$ & 0 & 0.2 & No & & 2 & 2 & 0 & 0 \\
\hline & $R$ & 0 & 0.2 & No & & 2.5 & 6 & 0 & 0 \\
\hline & $R$ & 0 & 0.2 & No & & 3 & 3 & 0 & 0 \\
\hline & $\mathrm{R}$ & 0 & 0.2 & No & & 3.4 & 2 & 0 & 0 \\
\hline & $R$ & 0 & 0.2 & No & & 4 & 7 & 2 & 0 \\
\hline & $R$ & 0 & 0.2 & No & & 3 & 1 & 1 & 0 \\
\hline & $\mathrm{R}$ & 0 & 0.2 & No & & 2 & 1 & 1 & 0 \\
\hline & $R$ & 0 & 0.2 & No & & 1 & 1 & 1 & 0 \\
\hline & $\mathrm{R}$ & 0 & 0.2 & Yes & & 1 & 6 & 3 & 2 \\
\hline & L & 0 & 0.2 & Yes & & 1 & 3 & 0 & 0 \\
\hline & L & 0 & 0.2 & Yes & & 2 & 2 & 0 & 0 \\
\hline & $\mathrm{R}$ & 0 & 0.2 & Yes & & 2.5 & 8 & 2 & 0 \\
\hline & $\mathrm{R}$ & 0 & 0.2 & Yes & & 3 & 4 & 0 & 0 \\
\hline & $\mathrm{R}$ & 0 & 0.2 & Yes & * & 3 & 4 & 0 & 0 \\
\hline & $\mathrm{R}$ & 0 & 0.2 & Yes & & 3 & 13 & 3 & 3 \\
\hline & $R$ & 0 & 0.2 & Yes & * & 3 & 5 & 4 & 0 \\
\hline & $\mathrm{R}$ & 0 & 0.2 & Yes & * & 2 & 9 & 3 & 0 \\
\hline & $\mathrm{R}$ & 0 & 0.2 & Yes & & 2 & 34 & 0 & 1 \\
\hline & $\mathrm{R}$ & 0 & 0.2 & Yes & * & 2 & 14 & 0 & 0 \\
\hline & $\mathrm{R}$ & 0 & 0.2 & Yes & & 2 & 9 & 0 & 0 \\
\hline & $R$ & 0 & 0.2 & Yes & * & 2 & 3 & 0 & 0 \\
\hline & $\mathrm{R}$ & 0 & 0.2 & Yes & & 2 & 3 & 0 & 0 \\
\hline & L & 0 & 0.2 & Yes & & 2 & 29 & 11 & 0 \\
\hline
\end{tabular}


Table 8, Continued.

\begin{tabular}{|c|c|c|c|c|c|c|c|c|c|}
\hline 8725 & Side & Delay & Duration (s) & Sig & EXT & $\mathrm{mA}$ & Sess & Omit & Equip \\
\hline & $\mathrm{L}$ & 6 & 0.2 & Yes & & 2 & 3 & 0 & 0 \\
\hline & L & 16 & 0.2 & Yes & & 2 & 4 & 0 & 1 \\
\hline & L & 0 & 0.2 & Yes & & 2 & 0 & 0 & 0 \\
\hline$\ddagger$ & L & 0 & 0.2 & Yes & & 7 & 0 & 0 & 0 \\
\hline
\end{tabular}


Table 9.

Experimental conditions experienced by subject $9360 .+$ indicates that the order of the food and shock were reversed (i.e., shock was administered immediately after a response and before food presentation). See the caption for Table 2 for a description of the rest of the data contained within the table.

\begin{tabular}{|c|c|c|c|c|c|c|c|c|c|}
\hline 9360 & Side & Delay & Duration (s) & Sig & EXT & $\mathrm{mA}$ & Sess & Omit & Equip \\
\hline & $\mathrm{L}$ & 0 & 0.2 & No & & 0 & 5 & 0 & 0 \\
\hline & L & 0 & 0.2 & No & & 2 & 3 & 2 & 0 \\
\hline & L & 0 & 0.2 & No & & 0 & 1 & 0 & 0 \\
\hline & L & 0 & 0.2 & No & & 2 & 2 & 2 & 0 \\
\hline & L & 0 & 0.2 & No & & 1 & 4 & 0 & 0 \\
\hline & L & 0 & 0.2 & No & & 1.5 & 11 & 2 & 0 \\
\hline & L & 0 & 0.2 & Yes & & 1.5 & 2 & 1 & 0 \\
\hline & L & 0 & 0.2 & Yes & & 1 & 9 & 0 & 0 \\
\hline & L & 0 & 0.2 & Yes & & 1 & 14 & 0 & 0 \\
\hline & $R$ & 0 & 0.2 & Yes & * & 1 & 4 & 0 & 0 \\
\hline & $R$ & 0 & 0.2 & Yes & & 1 & 5 & 0 & 0 \\
\hline & $R$ & 0 & 0.2 & Yes & * & 1 & 2 & 0 & 0 \\
\hline & $R$ & 0 & 0.2 & Yes & & 1 & 11 & 1 & 0 \\
\hline & $R$ & 0 & 0.2 & Yes & & 1.5 & 13 & 0 & 0 \\
\hline & $R$ & 0 & 0.2 & Yes & & 2 & 2 & 1 & 0 \\
\hline & $\mathrm{R}$ & 0 & 0.2 & Yes & & 1.5 & 1 & 1 & 0 \\
\hline & $R$ & 0 & 0.2 & Yes & & 2 & 22 & 0 & 1 \\
\hline & $R$ & 0 & 0.2 & Yes & & 2.5 & 7 & 0 & 0 \\
\hline & $R$ & 0 & 0.2 & Yes & * & 2.5 & 8 & 2 & 0 \\
\hline & L & 0 & 0.2 & Yes & & 2.5 & 11 & 0 & 0 \\
\hline & L & 0 & 0.2 & Yes & & 2.5 & 14 & 0 & 0 \\
\hline & L & 0 & 0.2 & Yes & * & 2.5 & 8 & 0 & 1 \\
\hline & $\mathrm{L}$ & 0 & 0.2 & Yes & & 2.5 & 4 & 0 & 0 \\
\hline & $\mathrm{R}$ & 0 & 0.2 & Yes & & 2.5 & 16 & 0 & 2 \\
\hline & L & 0 & 0.2 & Yes & & 2.5 & 9 & 2 & 2 \\
\hline$\ddagger$ & L & 0 & 0.2 & Yes & & 2.5 & 6 & 5 & 0 \\
\hline
\end{tabular}


occur on the key correlated with the delivery of the three shocks. When this criterion was satisfied, food was reinstated following a peck on this key.

If responding on the key associated with three shocks persisted or the removal of food presentation following a response on the three-shock key failed to produce long-term change, the contingencies associated with each key were reversed. That is, if three shocks previously were delivered following a response on the left key, the three shocks became correlated with the right key. This was done to determine if choice was maintained by the presentation of shocks or was correlated with spatial location (i.e., a side bias).

Based on the results of the choice-titration procedure, the differential aversiveness of one versus three shocks was questioned. In order to examine if one shock was more aversive than three, two subjects (2704 and 2746) returned to the initial VI-VI titration procedure. Response rates in this condition were considered stable when there was no upward or downward trend, and the means did not vary from the overall mean of the nine sessions by more than $20 \%$. This analysis was supplemented by visual inspection of the data. Response rates stabilized within 14 and 16 sessions for these two subjects. After response rates stabilized, the number of shocks presented in the presence of the red keylight was increased from one to three. The three shocks were delivered in the same manner as in the choice procedure (see above). Increasing the number of shocks delivered in the VI-VI context was done to assess if differential suppression was associated with one shock when compared to three shocks.

To assess whether having the houselight on during food presentation was interfering with the choice for the shocks, the houselight was turned off during food presentation but was present at the time of shock delivery. This manipulation was conducted with two subjects (2354 and 2704). 
As a final manipulation, the order of the food and shock presentation were reversed for two subjects. That is, a keypeck was immediately followed by a single shock (or three shocks, depending on the key). After shock delivery, food was presented and the trial continued as in the regular procedure.

\section{Results}

Initial training. Keypecking occurred within the first session for half of the subjects (four of eight). Within three sessions, all subjects were responding in the autoshaping procedure. Subjects continued to respond reliably during the VI training. The interval was extended to $30 \mathrm{~s}$ within seven sessions. Stable responding was achieved within 44 sessions for all subjects (range $=9$ to 44), with a mean of 17 sessions. Stable rates ranged from 23 to 94 responses per minute $(\mathrm{r} / \mathrm{min})($ mean $=58 \mathrm{r} / \mathrm{min})$ in the component associated with amber light and between 21 to 87 $\mathrm{r} / \mathrm{min}$ (mean $=59 \mathrm{r} / \mathrm{min}$ ) in the component associated with the red light. The implantation of the electrodes did not affect response rates, which were approximately the same in the presence of both stimulus lights.

Shock titration. Shock titration was successfully conducted with four subjects (2704, 2746, 2756, 5984) within 49 to 84 sessions. Moderately aversive stimuli were not identified for the other four subjects before it was determined that shock intensity would need to be determined in the context of the choice situation. Shock intensities of $2.0 \mathrm{~mA}$ to $5.5 \mathrm{~mA}$ were used to suppress rates of key-pecking by approximately 50\% relative to the shock-free condition. Individual subject data from the last phases of the VI titration procedure are presented in Figures 1 through 8, with one figure per subject. In these Figures, mean response rates (key pecks/min) from each component of the multiple VI-VI schedule are plotted as a function of session. The final experimental sessions of this condition are presented in these graphs. 
Choice titration. When the choice procedure began and shocks were first introduced, pecking was not maintained in six of the eight subjects, with subjects 2756 and 8725 as exceptions. This pattern of behavior is indicated in the second line of the Tables for the subjects other than 2756 and 8725 . At this point, an effective shock intensity was reassessed within the choice procedure.

The primary finding from the choice titration procedure was that more responses were allocated to the key correlated with the three shocks, despite the location of the key (i.e., the side). However, it seems that this could have been due to the development of a side-bias. See, for example, phases 1 and 2 of Figure 9. In these panels of this figure, the more responding is allocated to the right key; this level of responding persists even after the reversal of the side correlated with the three shocks. An increase in shock intensity was not sufficient to cause a reallocation of responding to the key correlated with the single shock. At some relatively high shock intensities, subjects ceased to peck either key instead of choosing the alternative that resulted in the delivery of fewer shocks. The only procedural change that consistently resulted in higher levels of responding on the key correlated with the single shock was the removal of food presentation following a peck on the key correlated with the three shocks. That is, choice patterns would reverse only when food was not delivered on the previously preferred 
Figure 1.

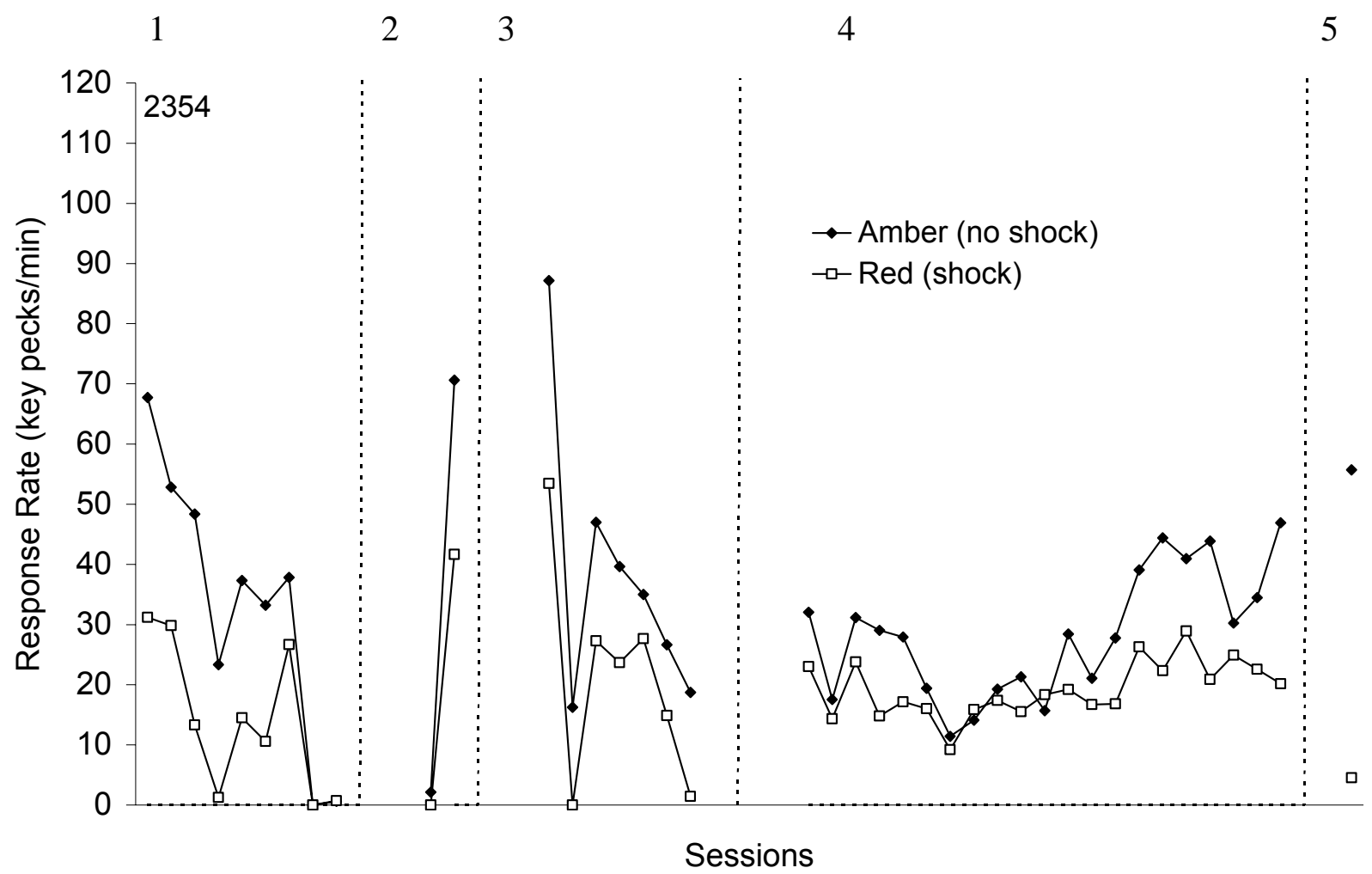

Figure 1. Responses per minute during the VI titration phase of the experiment for subject 2354. Data from the final 40 sessions are displayed. Closed diamonds indicate the response rate (key pecks/min) in the component where no shocks were delivered (i.e., with the amber light) and open squares indicate the response rate in the component where shocks were delivered (i.e., with the red light). Vertical dashed lines indicate changes in shock intensity and/or duration. Phases are numbered at the top of the graph and the numbers indicate the following: $1: 3 \mathrm{~mA}, 0.2 \mathrm{~s} ; 2$ : 0 mA; 3: $2 \mathrm{~mA}, 0.2 \mathrm{~s} ; 4: 0 \mathrm{~mA} ; 3.5 \mathrm{~mA}, 0.5 \mathrm{~s}$. This subject did not meet the stability criteria. 
Figure 2.

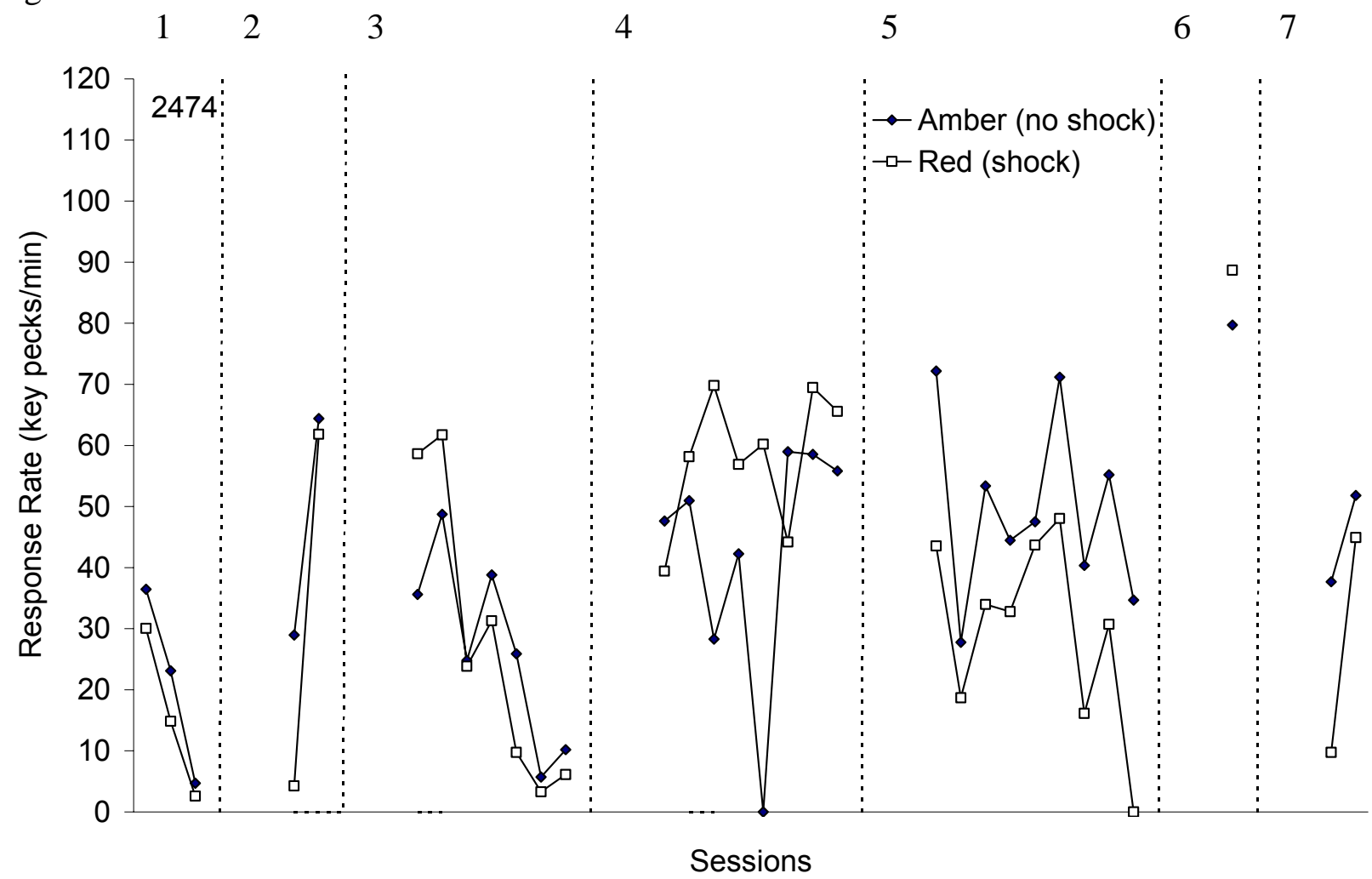

Figure 2. VI titration results from subject 2474. Data from the final 32 sessions are displayed. Closed diamonds indicate the response rate (key pecks/min) in the component where no shocks were delivered and open squares indicate the response rate in the component where shocks were delivered. Vertical dashed lines indicate changes in shock intensity; all shocks were $0.2 \mathrm{~s}$ in duration. Phases are numbered at the top of the graph and the numbers indicate the following: 1 : $4 \mathrm{~mA}$; 2: $0 \mathrm{~mA}$; 3: $2.5 \mathrm{~mA}$; 4: $0 \mathrm{~mA}$; 5: $2 \mathrm{~mA}$; 6: $0 \mathrm{~mA}$; 7: $2 \mathrm{~mA}$. This subject did not meet stability criteria. 
Figure 3.

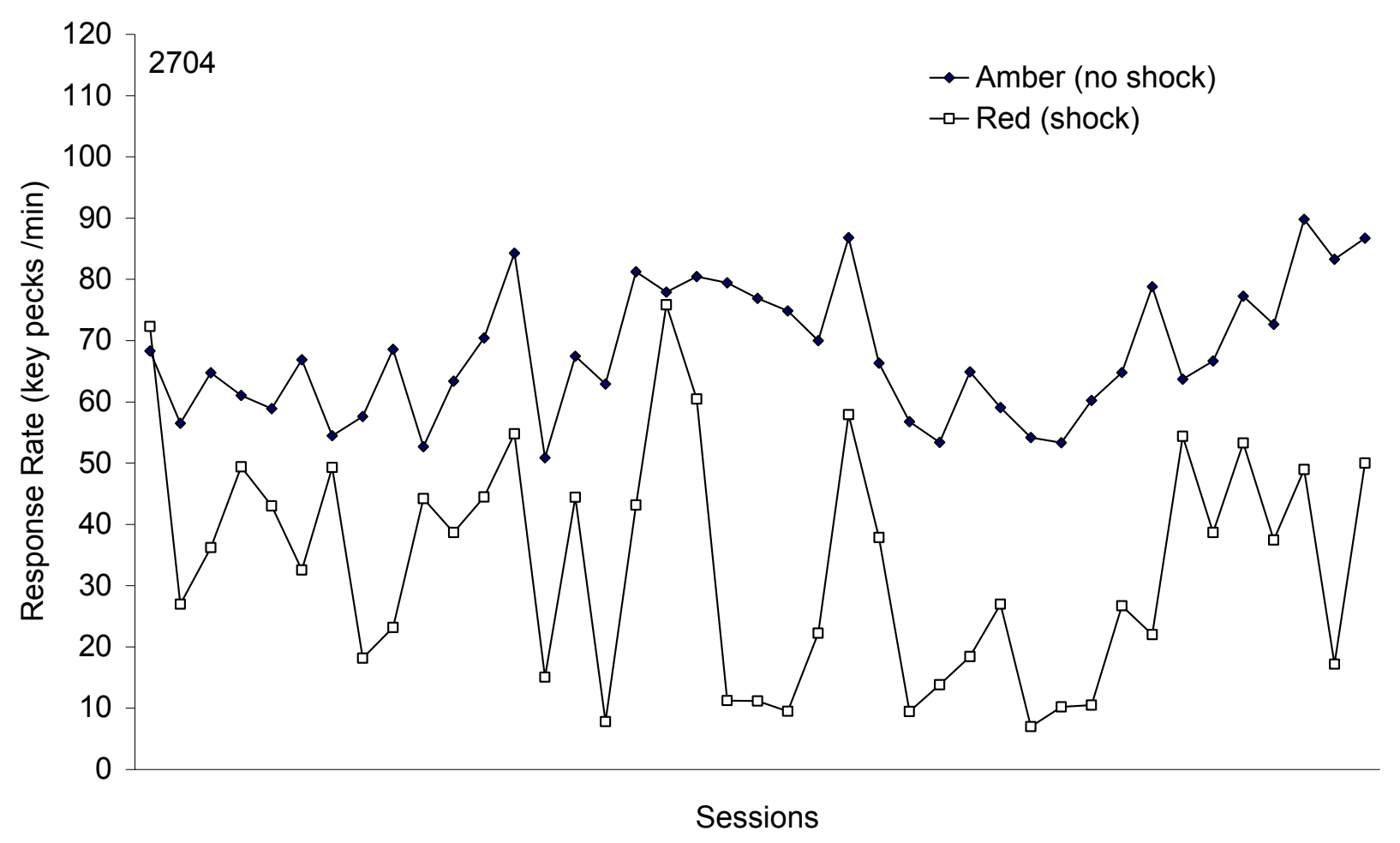

Figure 3. VI titration results from subject 2704. Data from the final 41 sessions are displayed. Closed diamonds indicate the response rate (key pecks/min) in the component where no shocks were delivered and open squares indicate the response rate in the component where shocks were delivered. All shocks delivered were of an intensity of $3.5 \mathrm{~mA}$ and a duration of $0.2 \mathrm{~s}$. This subject did meet the stability criteria. 
Figure 4.

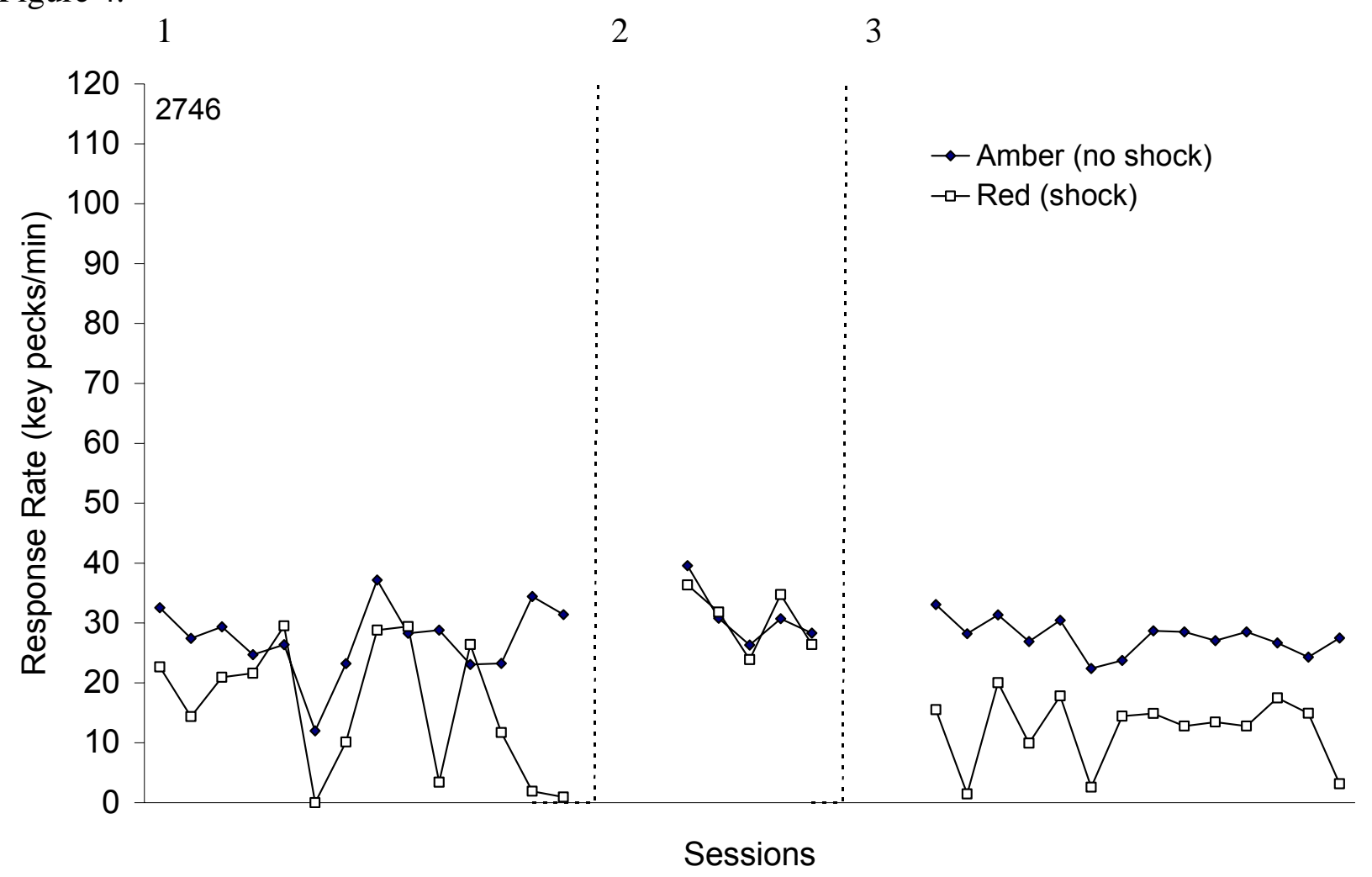

Figure 4. VI titration results from subject 2746. Data from the final 33 sessions are displayed. Closed diamonds indicate the response rate (key pecks/min) in the component where no shocks were delivered and open squares indicate the response rate in the component where shocks were delivered. All shocks delivered were $0.2 \mathrm{~s}$ in duration. Phases are numbered at the top of the graph and the numbers indicate the following shock intensities: 1: $2 \mathrm{~mA}, 2: 0 \mathrm{~mA}, 3: 2 \mathrm{~mA}$. This subject did meet the stability criteria. 
Figure 5.

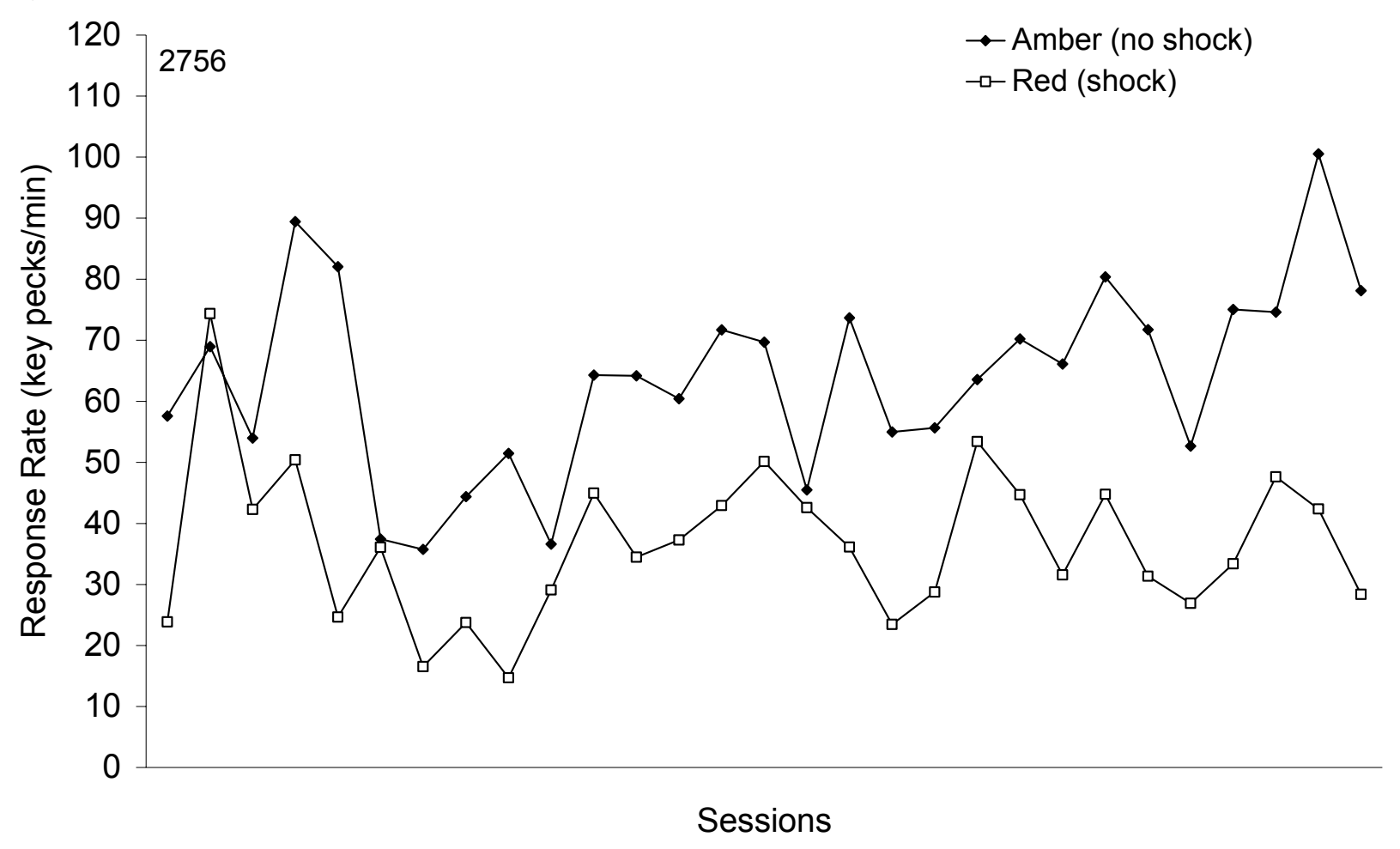

Figure 5. VI titration results from subject 2756. Data from the final 29 sessions are displayed. Closed diamonds indicate the response rate (key pecks/min) in the component where no shocks were delivered and open squares indicate the response rate in the component where shocks were delivered. All shocks delivered were $0.2 \mathrm{~s}$ in duration and $5.5 \mathrm{~mA}$ in intensity. This subject did meet the stability criteria. 
Figure 6.

12

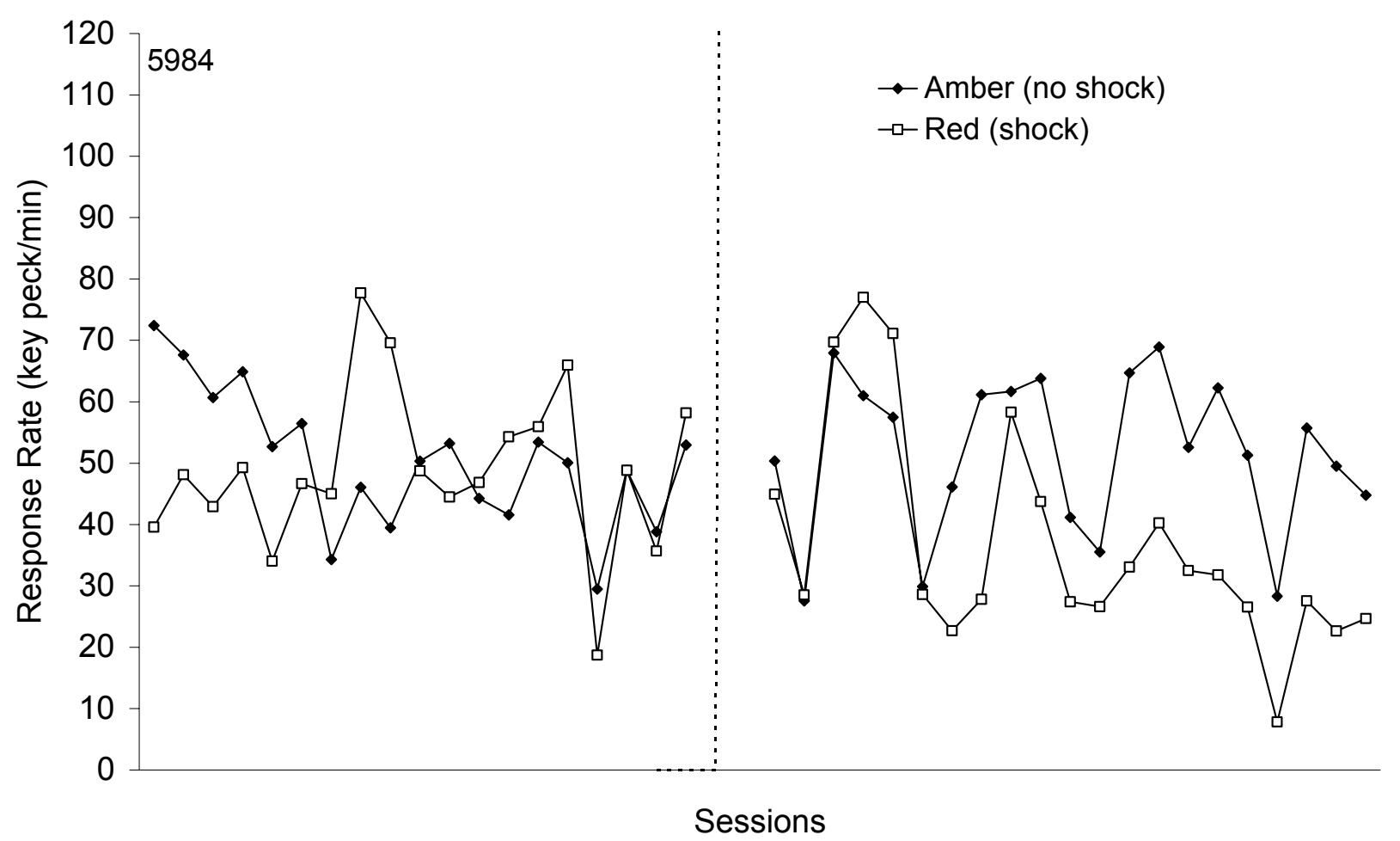

Figure 6. VI titration results from subject 5984. Data from the final 40 sessions are displayed. Closed diamonds indicate the response rate (key pecks/min) in the component where no shocks were delivered and open squares indicate the response rate in the component where shocks were delivered. All shocks delivered were $0.5 \mathrm{~s}$ in duration. Intensity varied from $5.0 \mathrm{~mA}$ (in phase 1) to $5.5 \mathrm{~mA}$ (in phase 2). This subject did meet the stability criteria. 
Figure 7.

1

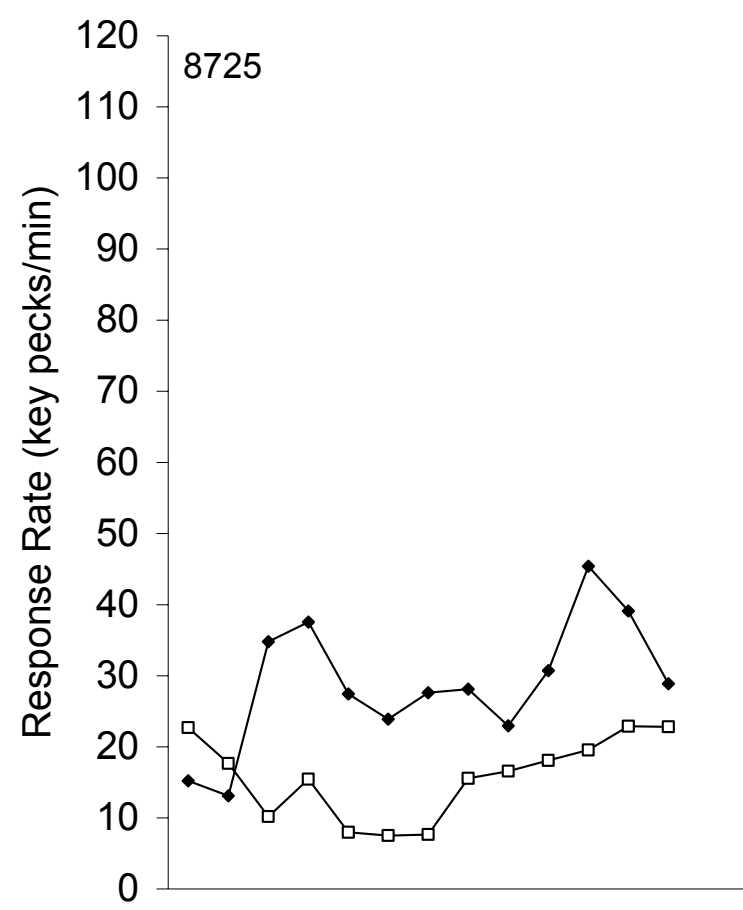

$\rightarrow-$ Amber (no shock) $\rightarrow-\operatorname{Red}($ shock)

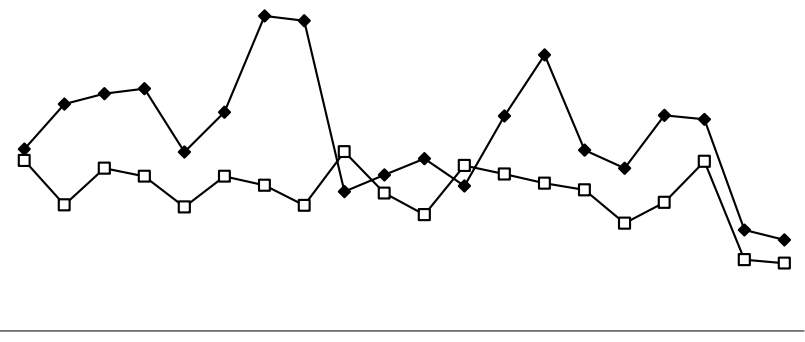

Sessions

Figure 7. VI titration results from subject 8725. Data from the final 33 sessions are displayed. Closed diamonds indicate the response rate (key pecks/min) in the component where no shocks were delivered and open squares indicate the response rate in the component where shocks were delivered. All shocks delivered were $0.5 \mathrm{~s}$ in duration. Intensity varied from $3.0 \mathrm{~mA}$ (in phase 1) to $3.5 \mathrm{~mA}$ (in phase 2). This subject did not meet the stability criteria. 
Figure 8.

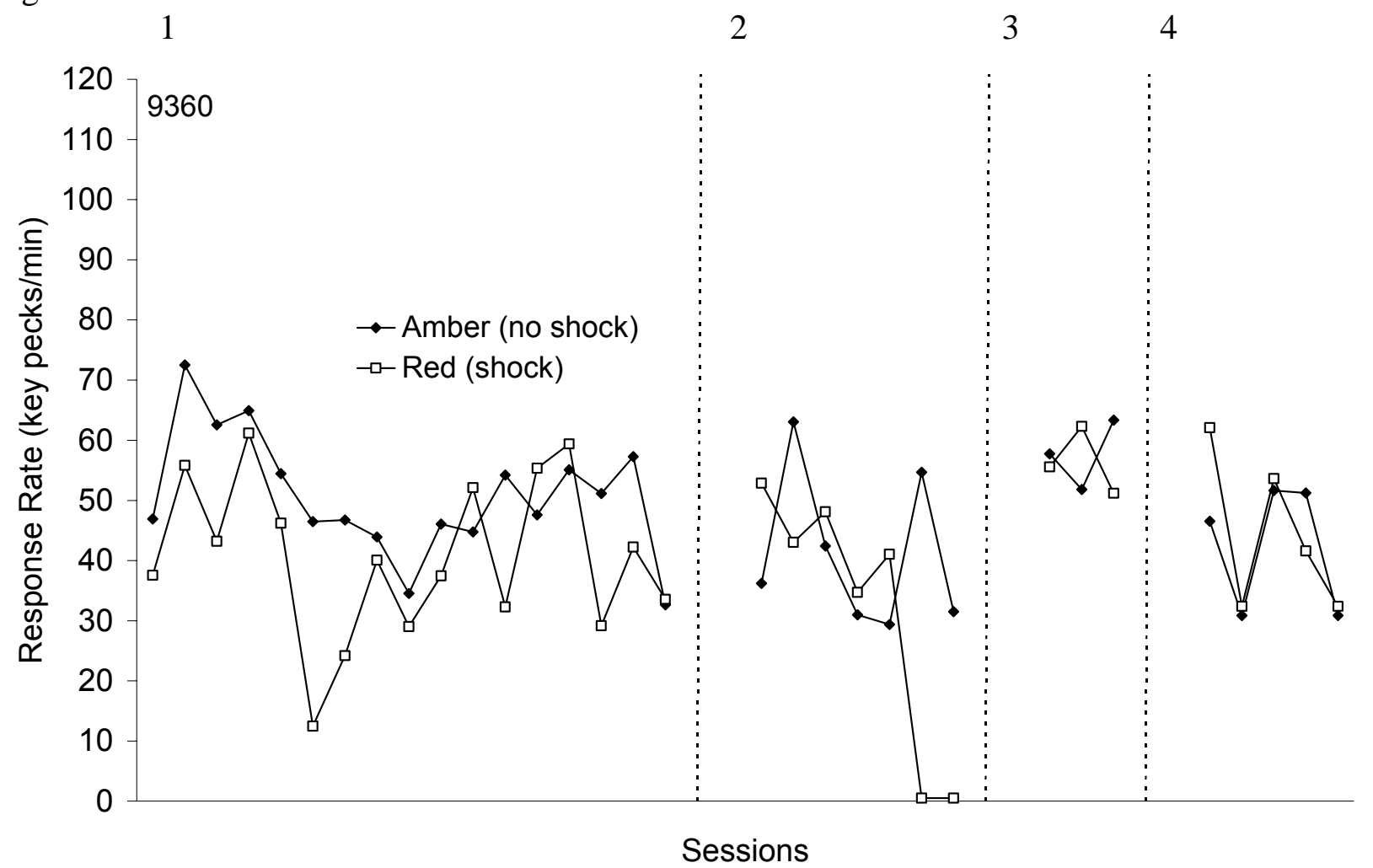

Figure 8. VI titration results from subject 9360. Data from the final 32 sessions are displayed. Closed diamonds indicate the response rate (key pecks/min) in the component where no shocks were delivered and open squares indicate the response rate in the component where shocks were delivered. Shock intensity and duration varied across phases; phase numbers are indicated at the top of the graph and indicate the following intensities and durations: $1: 3 \mathrm{~mA}, 0.2 \mathrm{~s}, 2: 3.5 \mathrm{~mA}$, $0.2 \mathrm{~s}, 3: 0 \mathrm{~mA}, 4: 2.5 \mathrm{~mA}, 0.5 \mathrm{~s}$. This subject did not meet the stability criteria. 
alternative. The conditions of the choice titration procedure are listed in Tables 2 through 8. Data from individual subjects in the final phases of the choice titration procedure are presented in Figures 9 through 16.

In phase 1 presented in Figure 9, there was a decrease in the percent choice for the three shocks following extended exposure to the three shocks on the left key. When the key correlated with the three shocks was reversed, however, percent choice did not reverse (phase 2). When food presentation was no longer available on the right key (phase 3), the pattern of response allocation reversed such that more keypecks were emitted on the left key. When food was reintroduced (phase 4), responding on the right key increased. Phases 5 and 6 contain percent choice when the houselight was turned off during food presentation; there seems to be no systematic effect of this manipulation in either phase. Response patterns similar to those presented in Figure 9 are evident in other subjects (see Figures 10, 12, 14, 15, and 16).

Overall, adjusting the intensity of the shock did not affect response allocation except in cases of complete suppression. See, for example, Figure 14, Phase 6. In this case, when the shock intensity was increased to $5.5 \mathrm{~mA}$, there was an initial suppressive effect on responding on the key correlated with the three shocks relative to when the shock was 5.0 mA. Eventually, the percent choice increased to approximately $50 \%$ before the complete suppression of the keypeck response was observed (represented by an open symbol). The increase in the intensity did not result in a switch in response patterns such that the three shocks were chosen less. Rather, complete suppression of the keypeck response was observed.

In Figure 13, data for subject 2756 are presented. Only two conditions are presented in this figure. These conditions correlate with a reversal of a side key when there was not differential responding between the alternatives (i.e., a mean of $40.83 \%$ responding on the three- 
shock alternative). Following the reversal (phase 2), percent choice for the three-shock alternative averaged 33.33\%. This change between conditions indicates a shift in response patterns such that the single-shock alternative was selected more frequently than the three-shock alternative. This is one of the few cases where behavior was under the differential control of the number of shocks delivered.

Introduction of delay. After more responses were consistently allocated to the key correlated with the single shock than the key correlated with the three shocks, and following a reversal of the side keys correlated with the single shock and the three shocks, delays were introduced between food presentation and the delivery of the three shocks. This condition was in effect for two subjects (2704 and 8725). Percent choice for the three-shock alternative in the condition in which there were delays intervening between the response and the three shocks are presented in Figures 17 and 18.

For subject 2704, when delays ranged from 0 to 16 s (Figure 17, top panel), percent choice for the three-shock alternative was as follows: 0-s delay: 7\%; 2-s delay: 43\%; 4-s delay: 30\%; 8-s delay: 43\%; 16-s delay: 30\%. Thus, when a 2-s delay was introduced, percent choice for the three-shock alternative increased to $30 \%$ and choice remained at or above this level for the remainder of the session. So, the presence or absence of the delay seemed to control behavior more than the specific delay value. This is in accordance with the expectation that delayed punishers should be less effective at suppressing behavior than more immediate punishers. When the delay values increased to $40 \mathrm{~s}$ (Figure 17, middle panel), the following pattern emerged: 0-s delay: 23\%; 5-s delay: 20\%; 10-s delay: 23\%; 20-s delay: 7\%; 40-s delay: 23\%. Here, percent choice was typically around $20 \%$, but there was a decrease in percent responding at the 20 -s delay block. This change was consistent for this subject throughout the five sessions of this 
Figure 9.

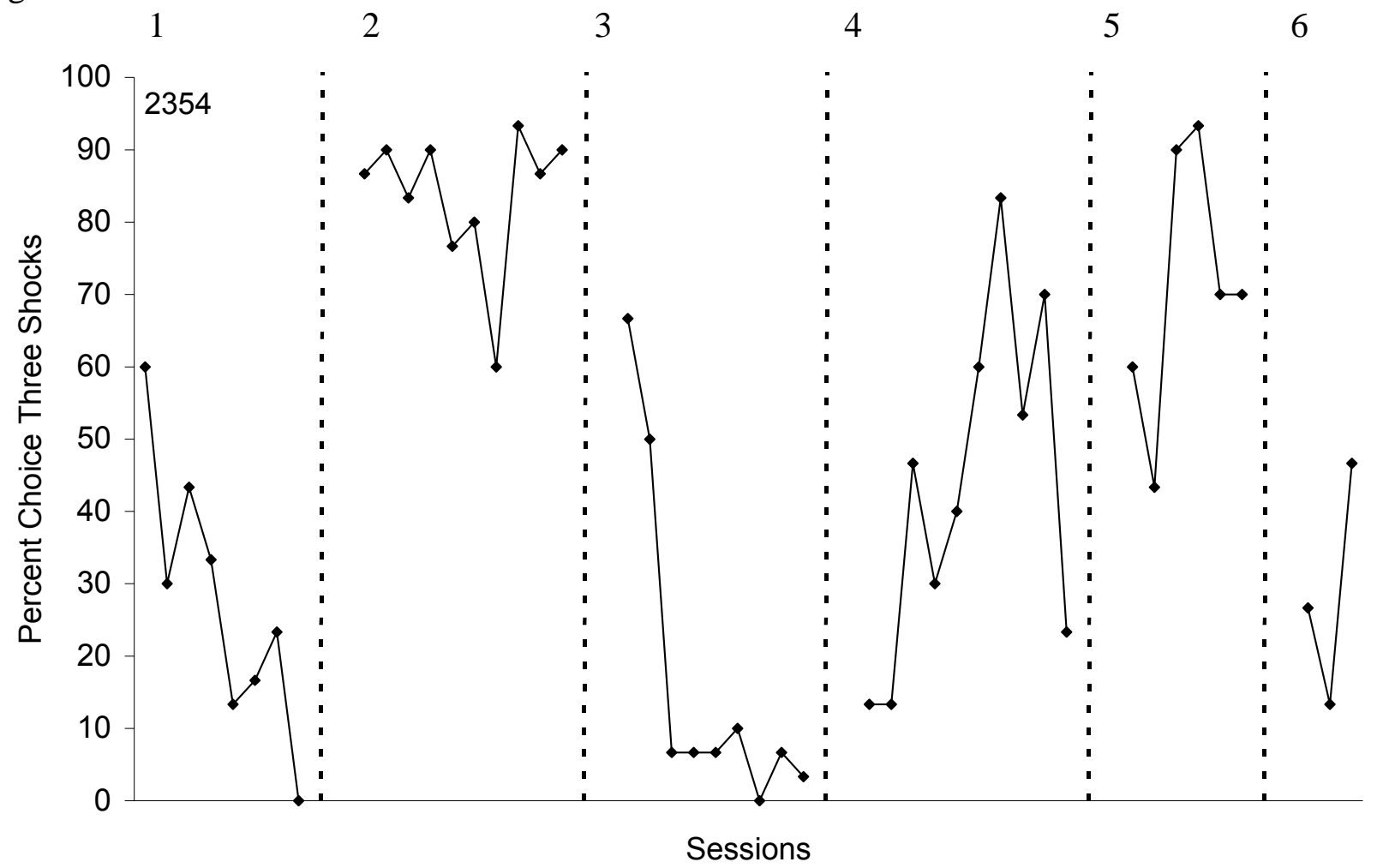

Figure 9. Choice titration data from subject 2354. Percent choice for the three shocks is plotted as a function of session. Shock intensity was $1.5 \mathrm{~mA}$ in phases 1 through 3 and $2.0 \mathrm{~mA}$ in phases 4 and 5. Shock duration was held constant at $0.2 \mathrm{~s}$ and there was a 0 -s delay between food and shock presentation. In phase 1, three shocks were delivered following a response on the left key; this was reversed in phase 2 . In phase 3 , no food was administered following right-key responses; food was reinstated in phase 4 . In phase 5 , the houselight was turned off during food presentation. In phase 6, the houselight continued to be extinguished during food presentation, but the key correlated with the three shocks was reversed (i.e., the left key was correlated with the three shocks). 
Figure 10.

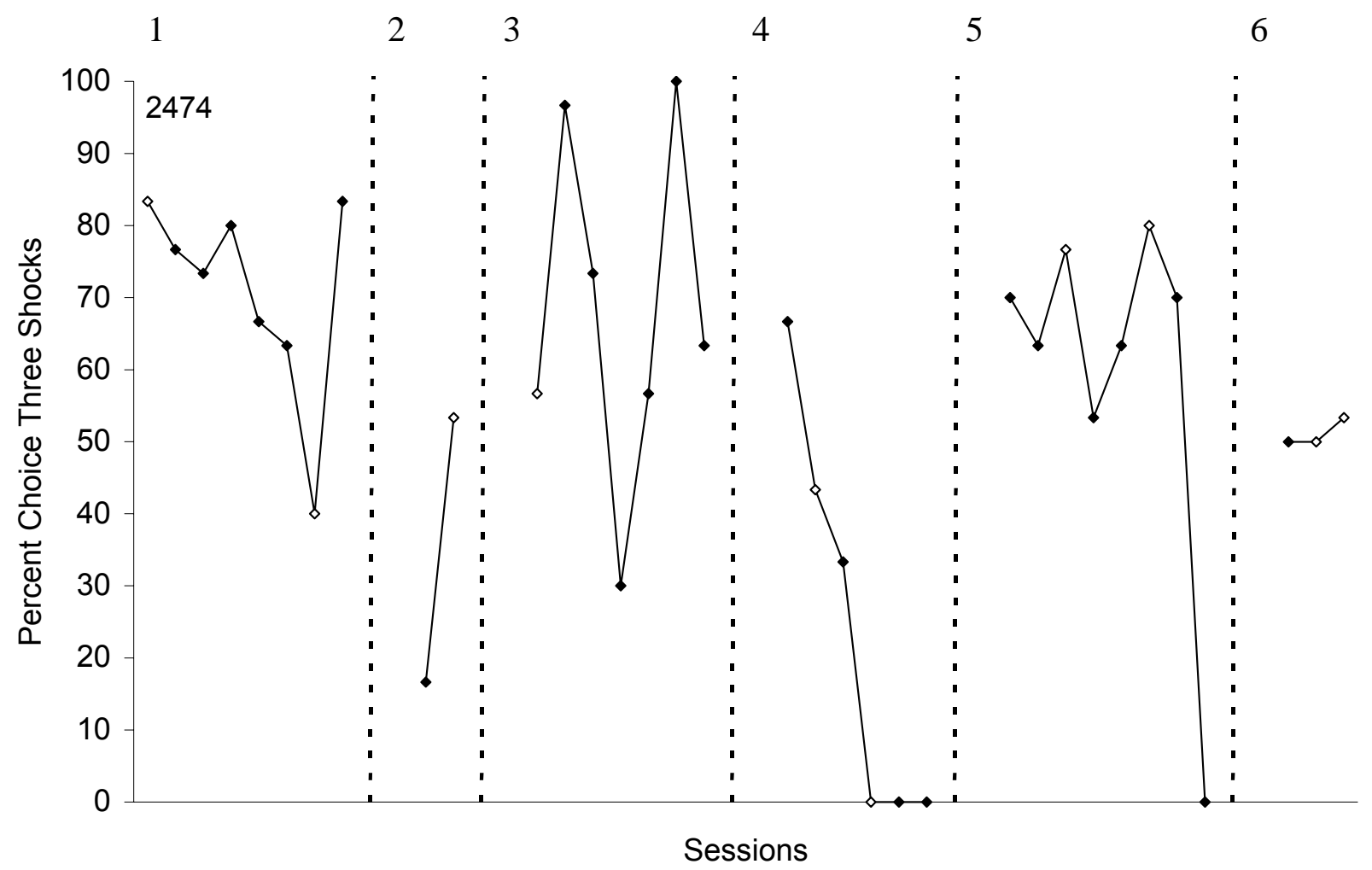

Figure 10. Choice titration data from subject 2474. Percent choice for the three shocks is plotted as a function of session. Open symbols indicate that there are intervening sessions that was terminated following 5 omitted trials, or in which there was an equipment malfunction (e.g., wires broke). Shock duration was held constant at $0.2 \mathrm{~s}$, always delivered at a 0 -s delay. Phases are numbered at the top of the figure. In phases 1-4, the three shocks were delivered following a response on the left key; in phases 5 and 6, three shocks were delivered following a response on the right key. In phase 1, shock intensity was $1.5 \mathrm{~mA}$; this was increased to $2 \mathrm{~mA}$ in phase 2, and reduced again to $1.5 \mathrm{~mA}$ in phase 3 . In phase 4 , no food was delivered following a response on the left key. In phase 5, food was available following responses on either key and the three shocks were delivered after responses on the right key. In phase 6, the houselight was turned off during food delivery. 
Figure 11.

1

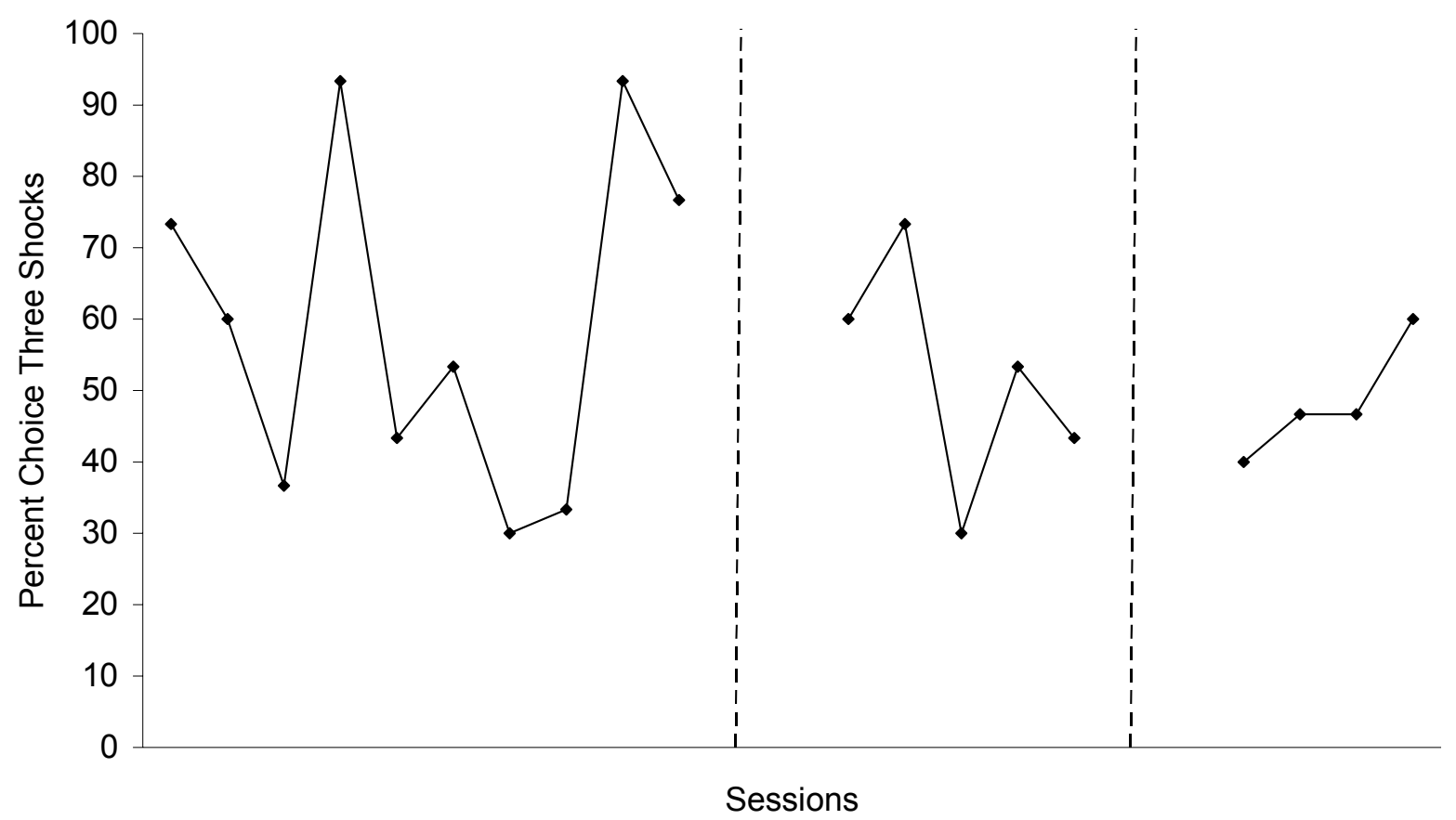

Figure 11. Choice titration data from subject 2704. Percent choice for the three shocks is plotted as a function of session. The data presented were obtained in sessions that followed the introduction of delays between the delivery of food and the delivery of shock. All plotted sessions contained 0-s delays to shock presentation. Open symbols indicate that there are intervening sessions due to the termination of the session because of omitted trials or in which there was an equipment malfunction (e.g., wires broke). The three shocks were delivered following a response to the right key. Dashed vertical lines indicate changes in the experimental conditions, details of which follow: Phase 1: $2 \mathrm{~mA}$; Phase 2: $2.5 \mathrm{~mA}$ and houselight off during food presentation; Phase 3: $0 \mathrm{~mA}$ and houselight off during food presentation. 
Figure 12.

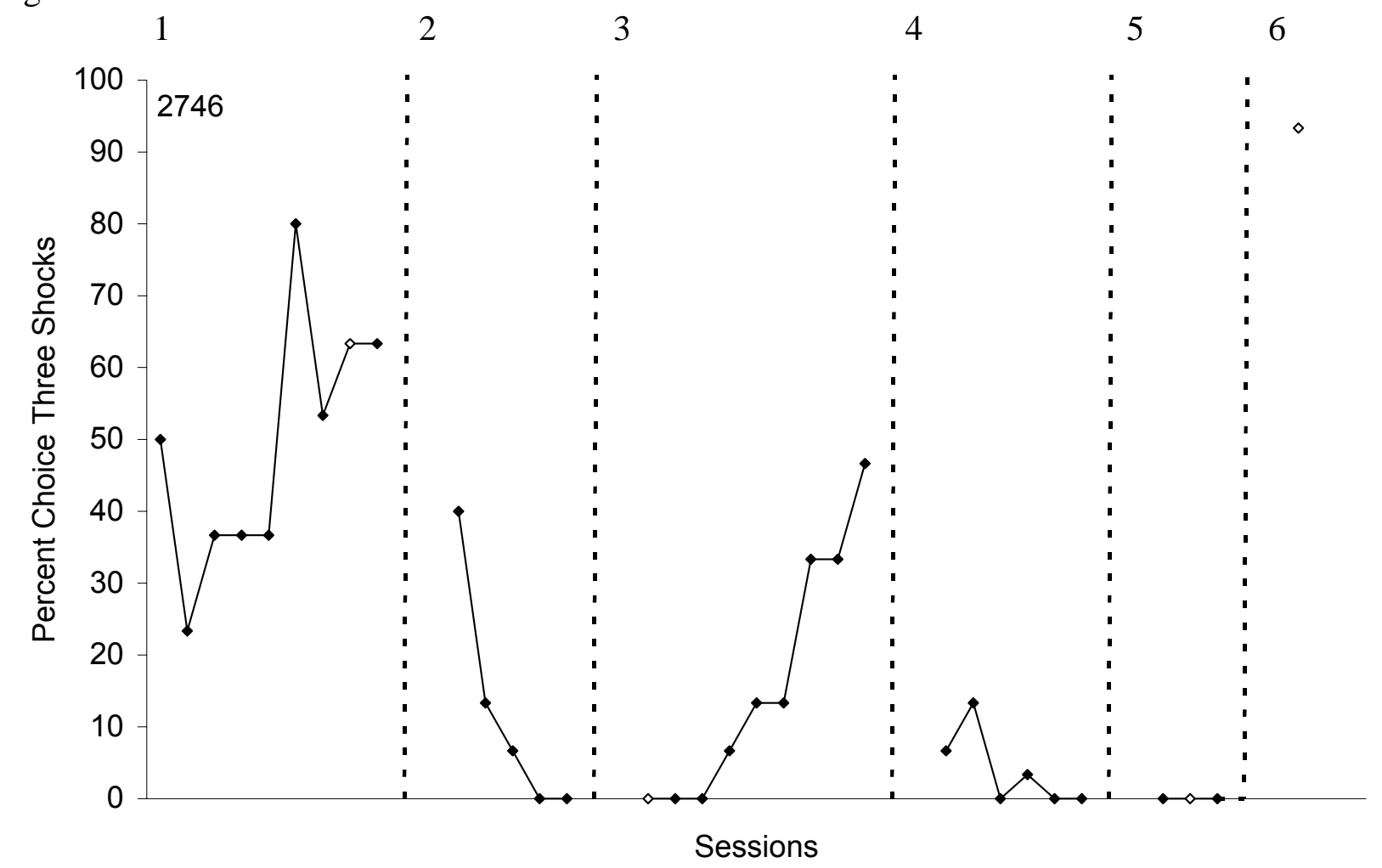

Figure 12. Choice titration data from subject 2746. Percent choice for the three shocks is plotted as a function of session. Open symbols indicate that there are intervening sessions that were terminated following 5 omitted trials or in which there was an equipment malfunction (e.g., wires broke). Three shocks were delivered following a response to the left key in phases 1-5 and the right key in phase 6 . All shocks were $2.0 \mathrm{~mA}$ in intensity in phases $1-4$ and $2.5 \mathrm{~mA}$ in phases 5-6. All shocks were $0.2 \mathrm{~s}$ in duration. Dashed vertical lines indicate changes in the presence or absence of food delivery following a response on the left key. Food was present in phases 1, 3, 5, and 6 and absent in phases 2 and 4 . 
Figure 13.

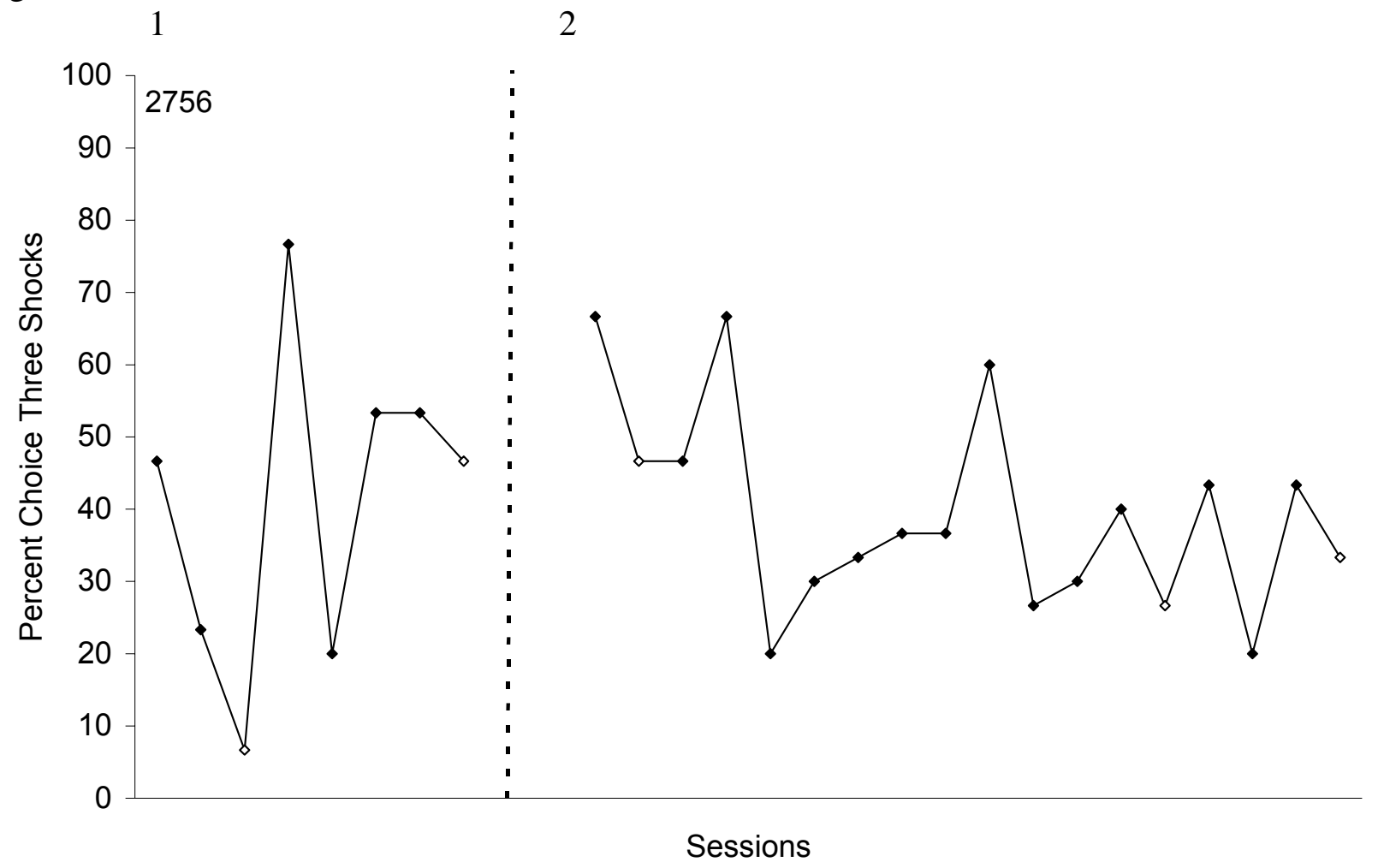

Figure 13. Choice titration data from subject 2756. Percent choice for the three shocks is plotted as a function of session. Open symbols indicate that there are intervening sessions which the subject terminated by not responding (an omission) or in which there was an equipment malfunction (e.g., wires broke). All shocks were $5 \mathrm{~mA}$ in intensity and $0.5 \mathrm{~s}$ in duration. In phase 1 , the three shocks were correlated with the right key; the final ten sessions for this condition are displayed (except for sessions that were terminated due to omissions). In Phase 2, the three shocks were correlated with the left key. All sessions from this condition are displayed. 
Figure 14.

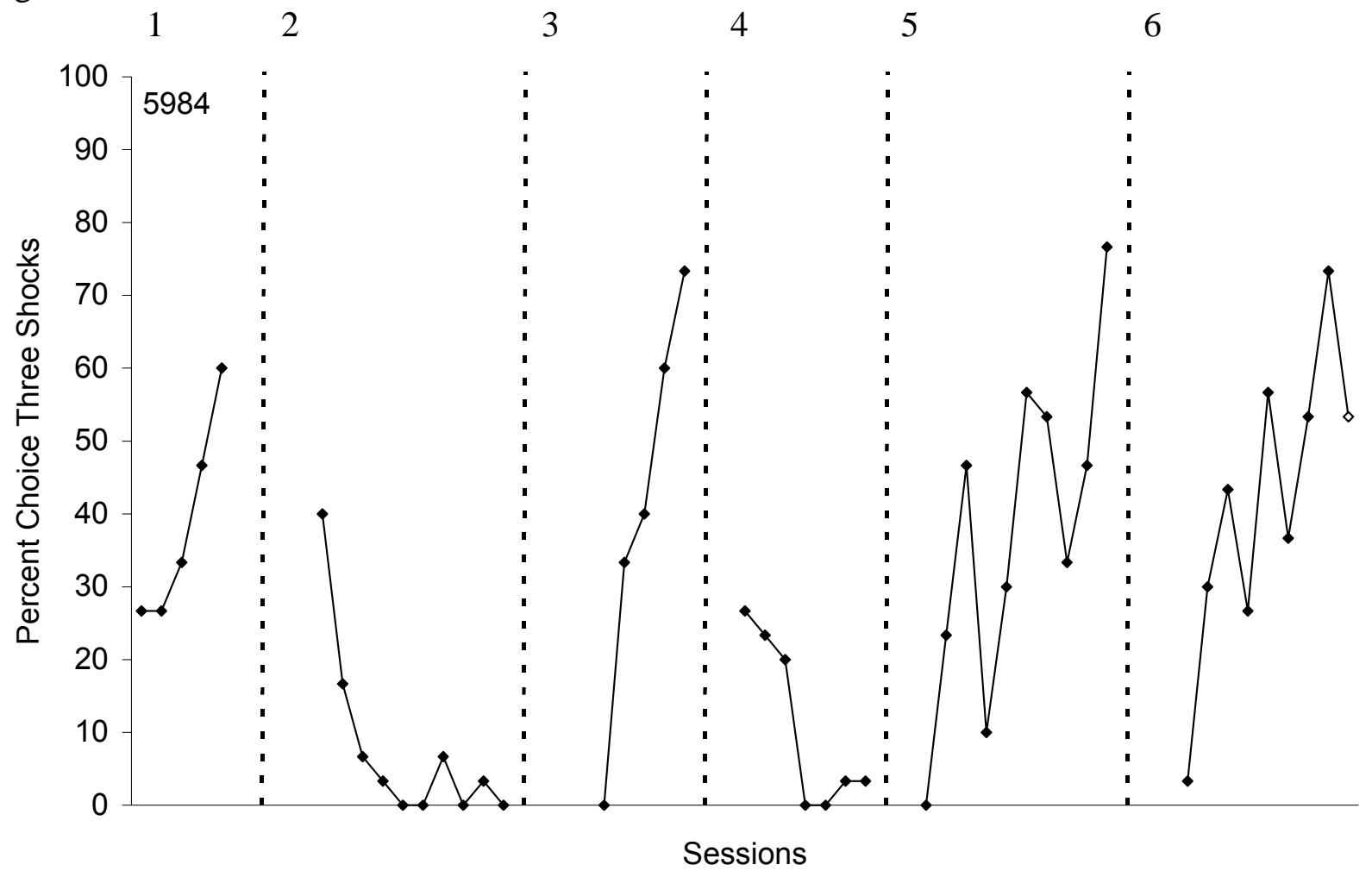

Figure 14. Choice titration data from subject 5984. Percent choice for the three shocks is plotted as a function of session. Open symbols indicate that there are intervening sessions that were terminated following 5 omitted trials or in which there was an equipment malfunction (e.g., wires broke). All shocks were $0.5 \mathrm{~s}$ in duration. Vertical dashed lines indicate changes in experimental conditions. Phases are numbered at the top of the graph and the numbers correspond to the following conditions: Phase 1: $4.5 \mathrm{~mA}$ shocks, with three shocks following responses on the right key; Phase 2: no food delivered following responses on the right key; Phase 3: food reintroduced; Phase 4: no food delivered following responses on the right key; Phase 5: food reintroduced following right-key responses and shock intensity increased to 5.0 $\mathrm{mA}$. Phase 6: shock intensity increased to $5.5 \mathrm{~mA}$. 
Figure 15.

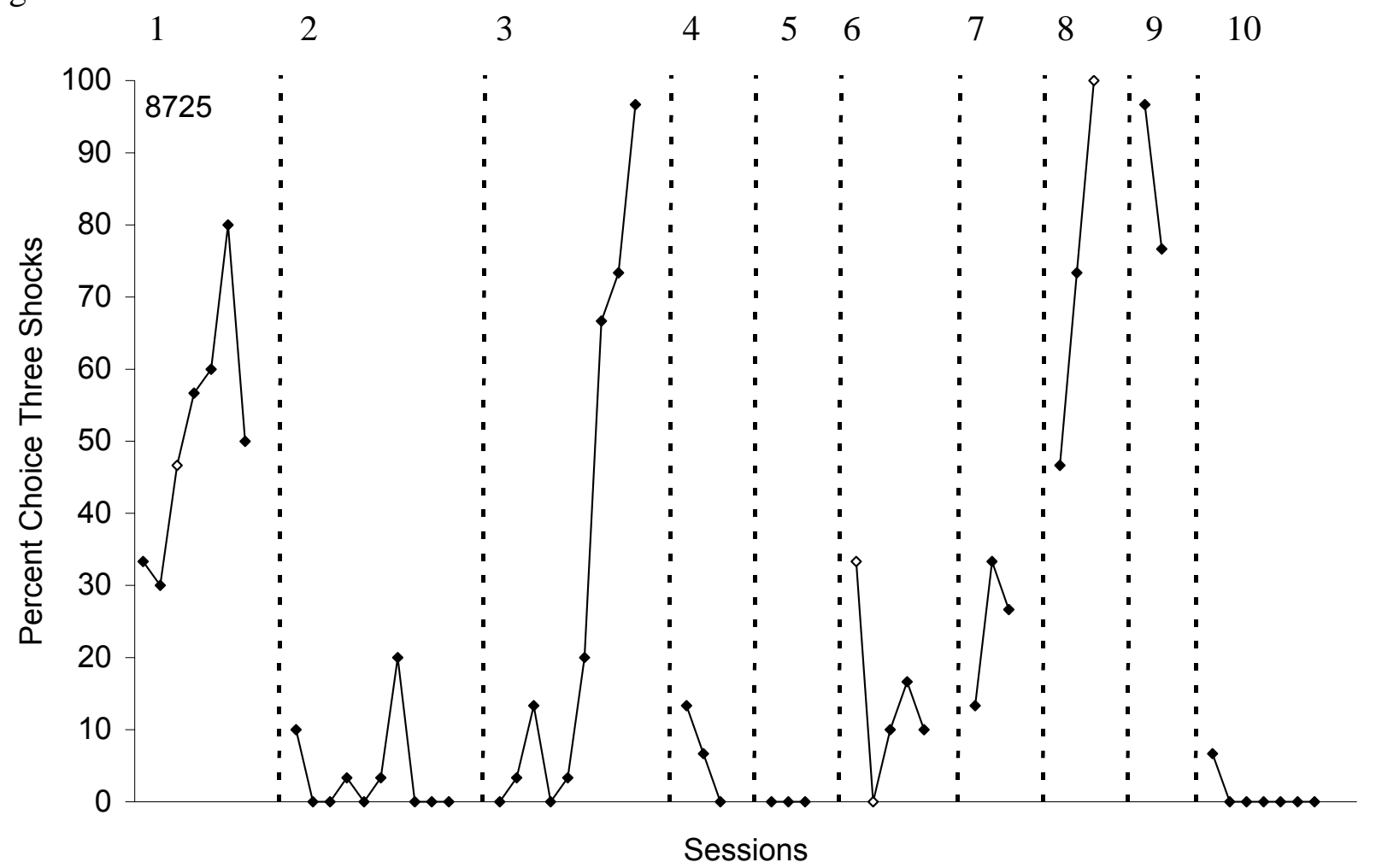

Figure 15. Choice titration data from subject 8725. Percent choice for the three shocks is plotted as a function of session. Open symbols indicate that there are intervening sessions that were terminated following 5 omitted trials or in which there was an equipment malfunction (e.g., wires broke). All shocks were $2.0 \mathrm{~mA}$ in intensity and $0.2 \mathrm{~s}$ in duration. Phases are numbered at the top of the graph and the numbers correspond to the following conditions: Phase 1: right key correlated with the three shocks; Phase 2: no food delivered following responses on the right key; Phase 3: food reintroduced on the right key; Phase 4: no food delivered following responses on the right key; Phase 5: food reintroduced on the right key; Phase 6: reversal such that three shocks were delivered following a response on the left key; Phase 7: 6-s delays in effect; Phase 8: 16-s delays in effect; Phase 9: 0-s delays in effect; Phase 10: shock preceded food presentation. This subject responded through all of these sessions with exclusive responding for the single shock. 
Figure 16.

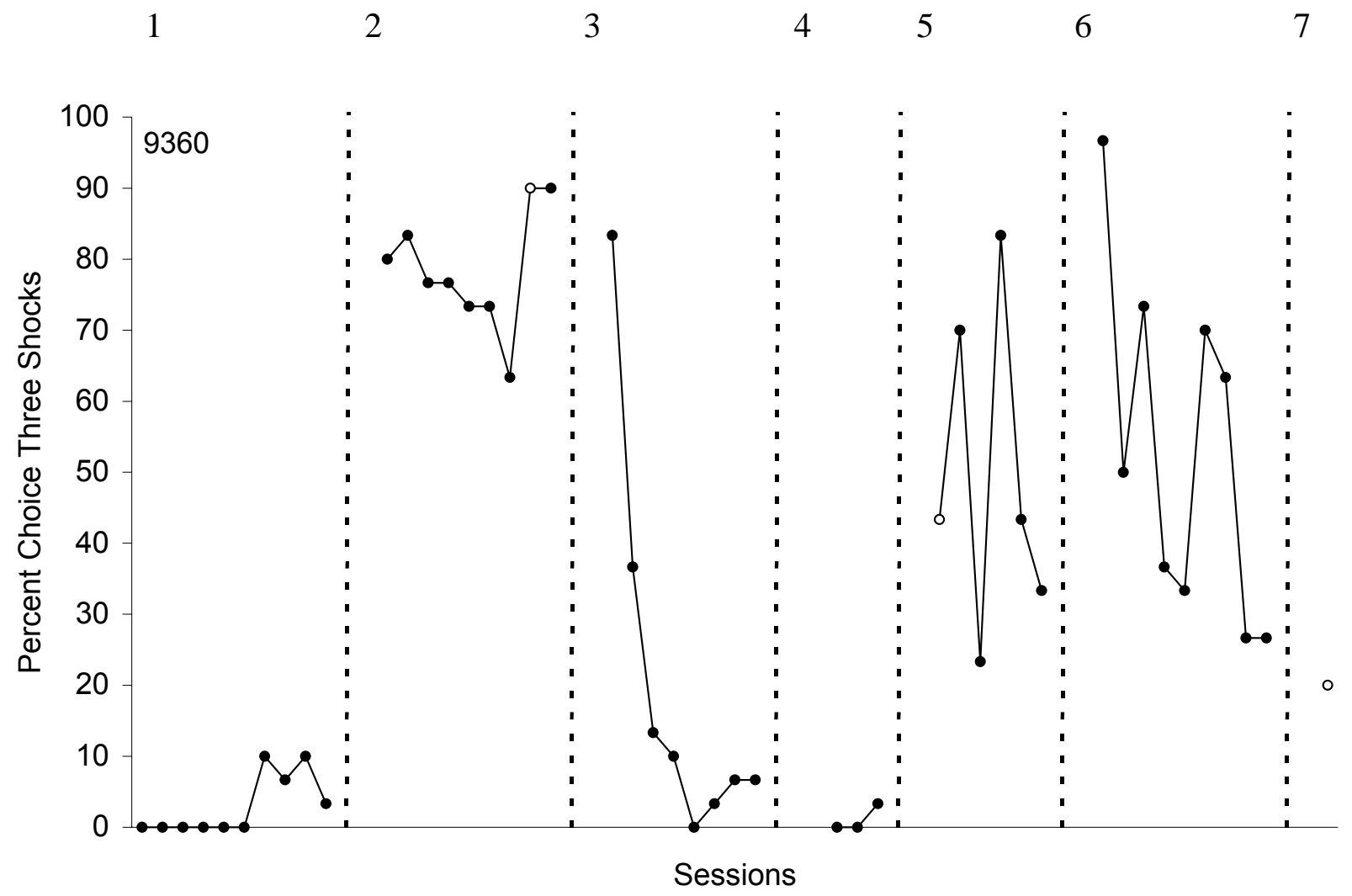

Figure 16. Choice titration data from subject 9360. Percent choice for the three shocks is plotted as a function of session. Open symbols indicate that there are intervening sessions that were terminated following 5 omitted trials or in which there was an equipment malfunction (e.g., wires broke). All shocks were $2.0 \mathrm{~mA}$ in intensity and $0.2 \mathrm{~s}$ in duration and delivered at a 0 -s delay. Open symbols indicate nonconsecutive sessions are plotted because the subject stopped responding through omissions in a preceding session. Phase changes are indicated by vertical dashed lines and phases are numbered at the top of the graph. Phase numbers correspond to the following conditions: Phase 1: right key correlated with three shocks; Phase 2: left key correlated with three shocks; Phase 3: left key correlated with 3 shocks and no food presentations (extinction); Phase 4: left key correlated with three shocks and food reintroduced; Phase 5: right key correlated with three shocks; Phase 6: left key correlated with three shocks; Phase 7: order of food and shock presentation reversed. In Phase 7, there was one omitted session before the plotted data point and four omitted sessions following the plotted session. 
condition, but is not consistent with this subject's behavior in other delay conditions. When terminal delay values were increased to $60 \mathrm{~s}$ (Figure 17, bottom panel), the following percent choice for the three-shock alternative were observed: 0-s delay: 63\%; 10-s delay: 53\%; 20-s delay: 57\%; 40-s delay: 60\%; 60-s delay: 30\%. In the final session of this condition, all keypecks in the free-choice trials were allocated to the alternative correlated with the three shocks. As there was not differential control over choice by the single-shock alternative and the three-shock alternative when 0-s delays were in effect (i.e., the first block), the experimental conditions were changed such that the delay values were all $0 \mathrm{~s}$.

Subject 8725 experienced two sets of delays, with $6 \mathrm{~s}$ and $16 \mathrm{~s}$ as terminal values (see Figure 18). When the set of delays in which $6 \mathrm{~s}$ was the maximum value (top panel), responding for the three-shock alternative occurred approximately $20 \%$ of the time, with $11 \%$ choice at the 0-s delay, 22\% choice at 1-, 4-, and 6-s delays, and 45\% choice at the 2-s delay. In the 16-s delay condition (bottom panel), responding was allocated exclusively to the key associated with the three-shock consequence in the final session. The mean percent choice for the three-shock alternative within each block was as follows: 0-s delay: 67\%; 2-s delay: 78\%; 4-s delay, 89\%; 8s delay: 94\%; 16-s delay: 78\%. After the fourth session, 0-s delays were reinstated because of the exclusive responding for the three-shock alternative. With this exclusive preference, it was difficult to draw any conclusions about the effects of delay on choice for the three-shock alternative.

Other procedural changes. If responding persisted on the key correlated with the delivery of the three shocks, the sides with which the single shock and three shocks were correlated were reversed. The reversal of the key with which the three shocks were correlated resulted in continued responding on that key, indicating that a side bias may have influenced choice (e.g., 
Figure 17.

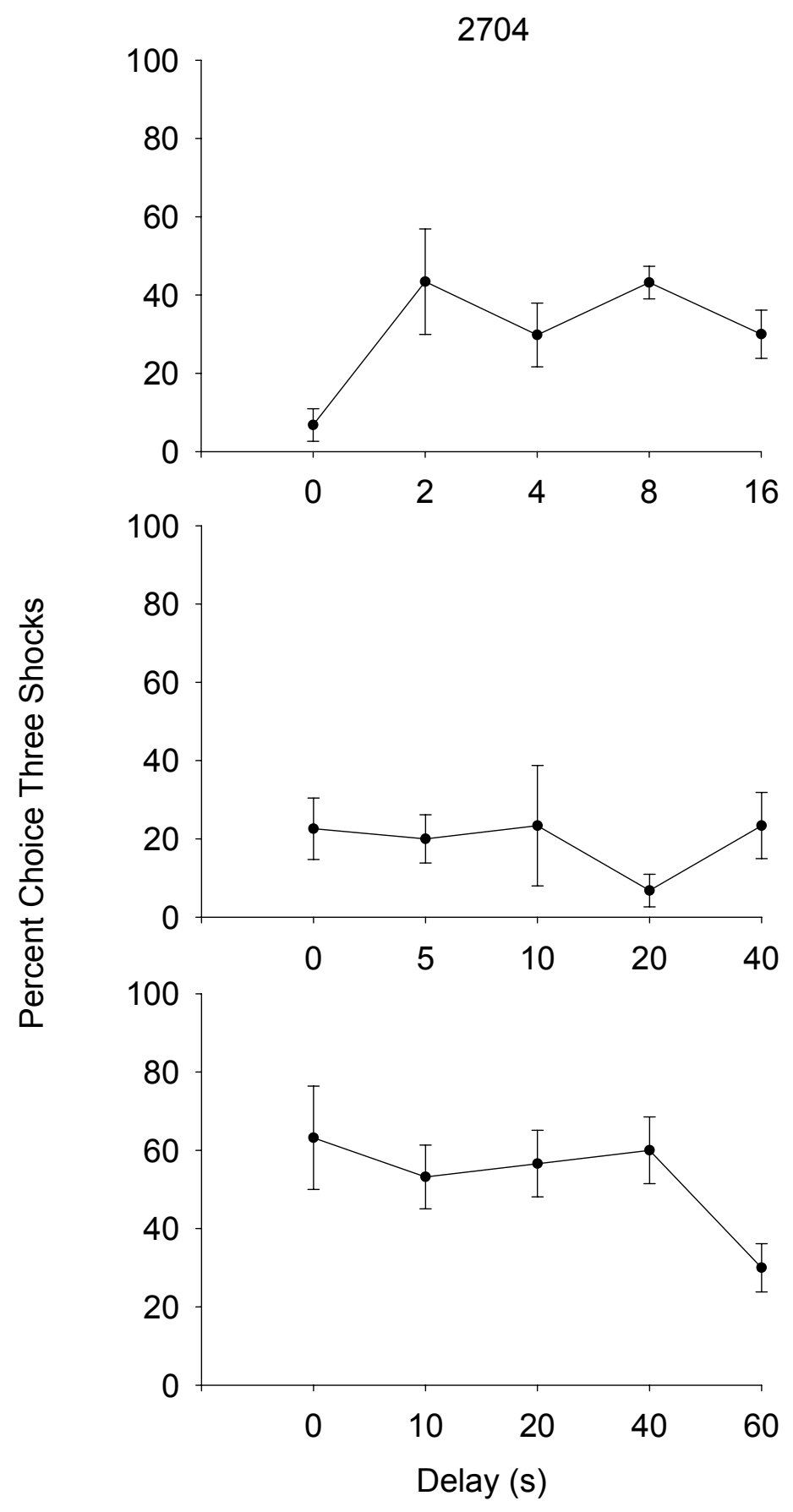

Figure 17. Performance in the choice procedure with delays introduced for subject 2704. The last five sessions of each condition are presented. Error bars represent the standard error of the mean. The top panel shows percent choice for the three-shock alternative when the maximum delay was $16 \mathrm{~s}$. The middle panel shows percent choice for the three-shock alternative when the maximum delay was $40 \mathrm{~s}$. The bottom panel shows percent choice for the three-shock alternative when the maximum delay value was $60 \mathrm{~s}$. After this condition, 0 -s delays were reinstated in all blocks of trials. 
Figure18.

\section{5}

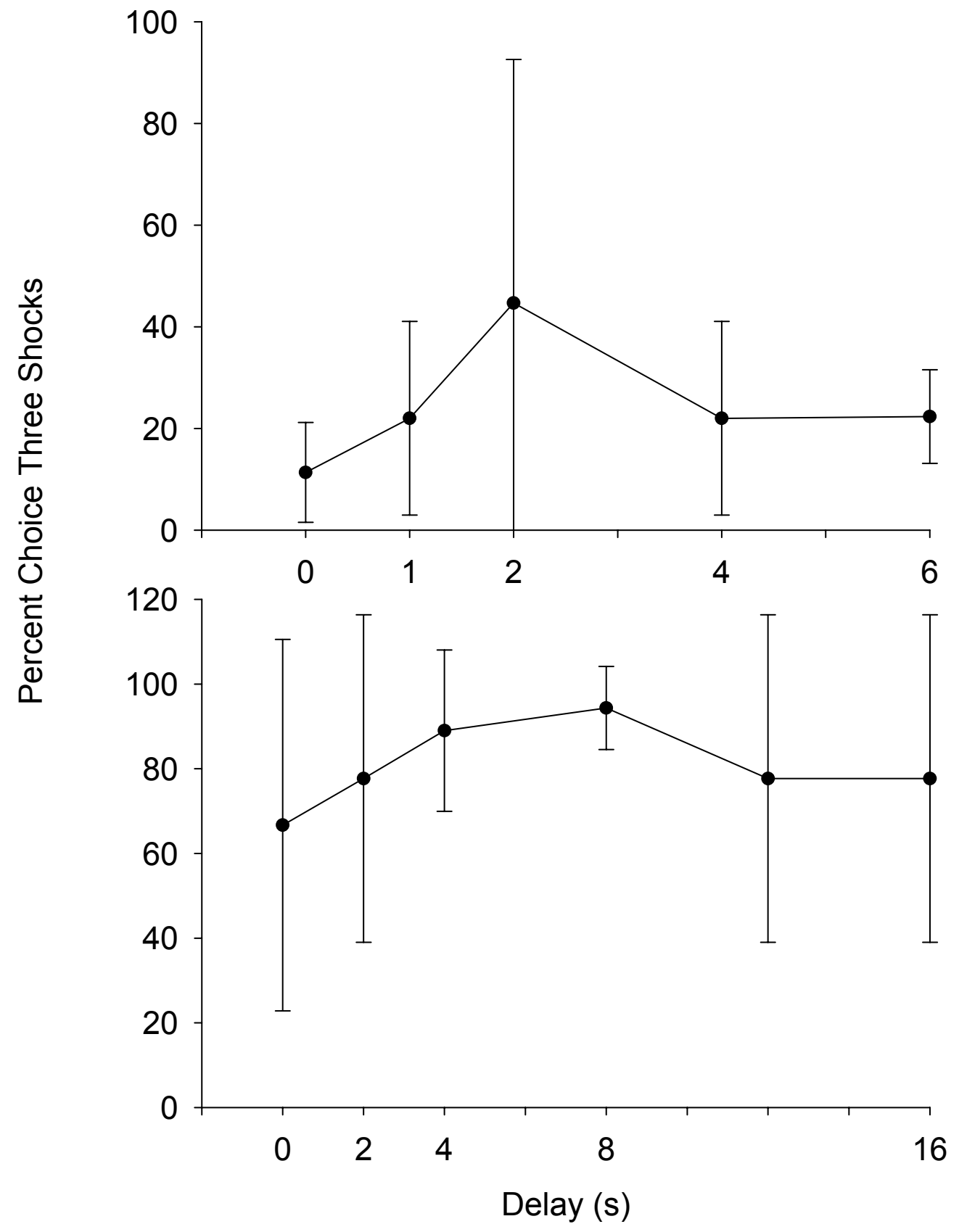

Figure 18. Performance in the choice procedure with delays introduced for subject 8725 . All sessions of each delay condition are presented. Error bars represent the standard error of the mean. The top panel shows percent choice for the three-shock alternative when the maximum delay was 6 s. The bottom panel shows percent choice for the three-shock alternative when the maximum delay value was $16 \mathrm{~s}$. 
see data from subject 2756 in Figure 13). The removal of food from the three-key alternative was successful in redirecting behavior such that more responses were allocated on the single-shock alternative than the three-shock alternative. See Figure 16 for an example of responding persisting on a given side key when contingencies are reversed but changing when food is removed.

After several sessions on the choice procedure in which they did not respond (i.e., omissions), two subjects were returned to the VI-VI titration procedure. After response rates stabilized in this procedure, three shocks were presented (instead of a single shock) following responses that satisfied the VI schedule. The return to the titration procedure indicated that the single shock and the three shocks did not have differential degrees of aversiveness associated with them, as indicated by the mean response rate $(\mathrm{r} / \mathrm{min})$ in each condition. The proportion of the average response rates in the food and shock component (red keylight) relative to the total average response rate in each of the final five sessions in each condition are presented in Figure 19. The degree of suppression in the three-shock condition does seem to be greater than in the single-shock condition, but in the last session, there seems to be an upward trend for both subjects. Given more experience with this condition, perhaps this variability would be minimized and more suppression would be evident.

In order to improve the discriminability of the shocks, the houselight was turned off during food presentation. Turning off the houselight during food presentation but continuing to flash the houselight when shocks were delivered did not seem to affect percent choice. That is, the percentage of responses allocated to the three-shock alternative was approximately the same when the houselight was turned off as when the houselight was on. Note the similar levels of responding in the final two phases of Figure 11 for support of this statement. 
Figure 19.

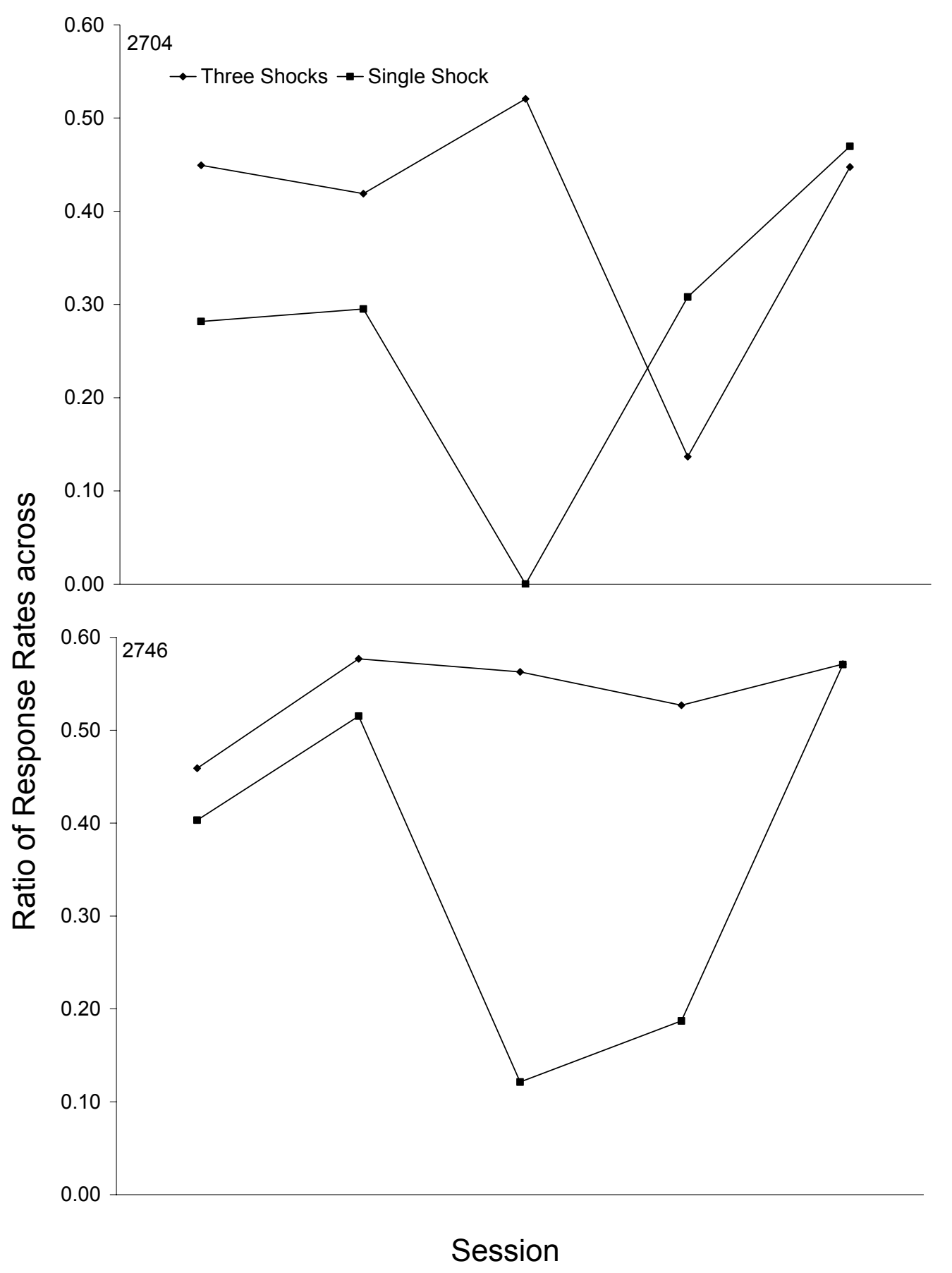

Figure 19. The ratios of the response rate (key pecks/min) in the presence of the red light (VI + shock) relative to the total response rate in the entire session (food and shock conditions) are presented in both the single-shock condition and the three-shock condition of the VI-VI titration procedure for subject 2704 (top panel) and 2746 (bottom panel). 
In the final manipulation, the order of food and shock presentation was reversed for two subjects (8725 and 9360). For subject 8725, this resulted in complete suppression of the key pecking (see the last line of Table 8). For subject 9360, key pecking continued, but the side that was favored reversed. That is, before the change in the contingency, this subject was responding at near-exclusive levels for the three shocks and after the change in the order of the shock and on the first day of the reversal of the contingency, this subject responded almost exclusively for the single shock (see Figure 15, Phase 3).

\section{Discussion}

In the present study, the use of response-dependent electric shock as a moderately aversive event did not result in consistent effects. Therefore, the initial plan to develop an animal model of choice between aversive events was not fulfilled. That is, the delay-discounting functions (as in Evenden \& Ryan, 1996) could not consistently be generated. Instead, the present experiment became the study of variables that resulted in choice being maintained by the presentation of the three shocks instead of the presentation of the single shock. The following discussion outlines the rationale used in this experiment as well as factors that may be have contributed to more response allocation to the alternative correlated with three shocks than to the alternative correlated with a single shock.

The first stage of the experiment involved a titration procedure using a multiple VI-VI schedule. The initial titration procedure was successful in identifying a moderately aversive stimulus for four of eight subjects. For these subjects, response rates in the presence of the stimulus correlated with the delivery of shock were between $40-60 \%$ of response rates in the absence of this stimulus. Once this criterion was satisfied, the scheduled consequences were changed such that choice could be assessed. In the choice procedure, shocks of the same 
intensity and duration were used with the expectation that the delivery of three of these shocks would be more aversive than the delivery of a single shock. The single shock was, for some subjects, functionally aversive. That is, the shock moderately suppressed keypecking in the VIVI titration procedure. After the change to the choice procedure, complete suppression of keypecking was observed, and it was necessary to titrate the shock intensity again within this new context.

The finding that the context of shock delivery affected responding is notable. In the VIVI titration procedure, subjects responded frequently, and some proportion of these responses was followed by the presentation of food and delivery of a shock. When the schedule of reinforcement and punishment was changed to an FR 1 (as in the choice situation), the same consequence (the food presentation and shock delivery) resulted in greater response suppression. The change in the degree of aversiveness between these two contexts can be explained, in part, in terms of the properties of response-contingent punishers in VI schedules relative to other types of schedules. Arbuckle and Lattal (1992) commented on various aspects of behavior when contingencies of response-contingent reinforcement and punishment are arranged within the context of VI schedules. Specifically, Arbuckel and Lattal discussed the probability of a shock given a response in a VI schedule. When a VI schedule is in effect, the probability of a shock following a response is constantly changing due to the passage of time. Shock delivery becomes progressively more likely as each consecutive response is emitted. It is a small conceptual leap to imagine that as this correlation between responding and shock increases, responding becomes more aversive. This increase in aversive stimulation may be conceptualized in the same way that Dinsmoor (1954) describes avoidance procedures. That is, every response that is not the avoidance response is correlated with shock and therefore becomes aversive. 
Compared to the VI situation, where shock delivery changes in probability as time elapses and each response occurs, an FR 1 schedule may result in greater aversive stimulation. Shock is delivered following each response in an FR 1 schedule (as opposed to some number of response in the VI schedule). Based on the probability of shock presentation following a response, the VI schedule may generate more responding than an FR 1. Thus, lower shock intensities may be required to completely suppress behavior within the context of the FR 1 schedule of punishment delivery. The difference in the probabilities of shock may explain complete suppression within the choice procedure with a shock of the same intensity that moderately suppressed behavior in the VI condition.

Throughout the titration process in the choice context, contrary to the predictions about the aversive nature of multiple shocks, more responses were allocated to the key correlated with the three shocks than were allocated to the key correlated with a single shock. Increasing the shock intensity did not consistently result in decreased choice for the three shocks. Instead, complete suppression of keypecking was frequently observed. When the correlation between the response and food was removed (as in the extinction phases) and responses on one alternative resulted in three shocks but not food presentation, pecking was redirected to the key correlated with the presentation of food and the single shock. Based on this observation, it seems that the food delivery and shock presentation interacted in some way, resulting in maintained responding on the three-shock alternative. This interaction between food and shock could be characterized in at least two ways. In one conceptualization, it could be that the immediate delivery of the food was so reinforcing that the aversive events, delivered at a brief delay (i.e., $3 \mathrm{~s}$ ), did not affect choice. In the other model, perhaps the shocks, by virtue of following food presentation, became conditioned reinforcers. However, neither explanation is compelling. 
During most of this experiment, the shocks were delivered immediately following food presentation. Thus, there was a 3-s delay between the keypeck and the shock delivery. Just as delayed reinforcers are often less effective than immediate reinforcers (as in the delaydiscounting paradigm, for example), delayed punishers have been demonstrated to be less effective than immediate punishers in terms of behavioral suppression. For example, Baron, Kaufman, and Fazzini (1969) demonstrated that delays between 5 and $10 \mathrm{~s}$ disrupted the suppressive effects of electric shocks with rats. In the present study, when the shocks were presented before the food (and, therefore, at a shorter delay), subject 8725 responded such that fewer shocks were experienced and subject 9360 stopped pecking. The decrease in pecking suggests that the immediate presentation of the shocks was more aversive than the delayed shock presentation. Apparently the reversal of the order of these consequences resulted in a more effective punisher and differential control by the single shock and the three shocks. A test that would be necessary to assert this control would be a reversal in the side keys correlated with the single shock or the three shocks.

Throughout this experiment, the delivery of shock was perfectly correlated with the presentation of food, and shocks were delivered immediately following the presentation of food. It seems feasible that the presentation of the food was an amply potent reinforcer that through repeated exposure to the pair of stimuli, the shock delivery gained some reinforcing efficacy. However, this would require effective backwards conditioning, which seems unlikely. Perhaps a more compelling argument would be that the subjects were simply indifferent—responding was, by and large, not differentially affected by the delivery of a single shock or three shocks.

It seems more plausible that, with the consistent shock-food pairings, food may have adopted conditioned punishing effects (cf. Lerman and Vorndran, 2002 for a discussion of 
conditioned stimuli). This notion is supported by observations that subjects stopped pecking the keys. The subjects were, after all, food deprived and the only way to gain access to grain during the experimental sessions was to peck a key. The stimulus compound of the food paired with the shock must, by definition, have acquired aversive properties, since the subjects would avoid making a response on the key under some conditions. It is difficult, however, to disentangle the aversive nature of the food from the aversive nature of the shock (just as it is difficult to disentangle the conditioned reinforcing effects from the presentation of the primary reinforcer, in the above discussion). Anecdotally, however, the food hopper seemed to acquire aversive properties. That is, when the hopper would be raised for response-independent food delivery (as when a subject failed to respond in previous sessions), the subjects would shake and not approach the hopper. The shaking (a physiological response) would intensify when the hopper would drop, which has a discriminable sound and was temporally proximal to delivery of shock. When observed in the experimental sessions, it seemed that the subjects would approach the hopper and back away after a brief period of food access, as a result of past experience with the pairing between food presentation and shock delivery.

When experimental subjects have been given the choice between shock delivery following an operant response (e.g., maze-running) or a consummatory response (e.g., drinking), subjects responded more to produce the shock following maze running. Rodriguez and Logan (1980) presented a study in which rats could choose to run down one of two alleys. Running down one alley resulted in the presentation of a shock followed by the opportunity to consume water. Selection of the second alley resulted in shock that followed the opportunity to drink. The rats ran down the alley that resulted in a shock immediately after running more frequently than the alley that resulted in shock presentation following water consumption. Thus, it seems that it 
was less aversive to experience shock after running than after drinking. This finding may have some bearing on the delivery of shock following food delivery as opposed to after food delivery as used in the current experiment. Regardless of the specific relation between food and shock, it is clear that these two environmental events did interact in the present study and may have caused procedural difficulty.

Alternatively, perhaps the failure to respond differentially to the single shock and the three shocks stems from a failure to discriminate between these alternatives. In order to address these concerns, two procedural modifications were made to increase salience: (1) flashing the houselight when the shocks were delivered and (2) turning off the houselight during food presentation. Despite these changes, behavior did not systematically change, indicating either: (1) the modifications did not increase the salience of the shocks or (2) the three shocks were not more aversive than the single shock.

In order to assess whether the multiple shocks were more aversive than the single shock, two subjects were returned to the VI-VI titration procedure. The schedules in this phase of the experiment were VI 30-s schedules of reinforcement. In one component, only food was delivered according to this schedule. In the second component, food was delivered followed by three shocks, as in the choice procedure. The addition of the three shocks did result in a decrease in response rates, but the difference was not statistically significant. Perhaps with continued experience with three shocks in the titration procedure the results would have been statistically significant. Based on the statistical analysis, it seemed that the presentation of three shocks was not more aversive than a single shock in the present experiment. Thus, although there were structural similarities between the procedure employed in the current study and the Evenden and 
Ryan (1996) study, the delivery of multiple shocks did not function in an analogous way as the delivery of multiple food pellets.

To evaluate the role that spatial location (i.e., side bias) may have played in maintaining responding on the three-shock alternative, two changes were made. First, throughout the experiment, the sides correlated with the three shocks and the single shock were reversed. Following the reversals, subjects typically continued to respond on the side key that they had been responding on prior to the reversal. This indicates that behavior was not clearly controlled by shock presentation. It is important to note that the experimental histories of the subjects in the present experiment are unknown. These subjects may have had extensive experience responding only on the right key, for example, which may have affected the outcomes of the present study. Without the knowledge of the prior histories of the subjects, it is necessary to qualify the conclusions drawn from this study.

Response-maintenance problems. Throughout the experiment, it was difficult to maintain key pecking. With higher shock intensities, complete keypeck suppression was observed instead of a change in response allocation to the selection of fewer shocks. This may be an example of the all-or-none suppressive effects of electrical shock, and may represent the typical difficulties associated with working with response-dependent shock (cf. Arbuckel and Lattal, 1992). Hake, Azrin, and Oxford (1967) define this all-or-none effect succinctly as "responding at the prepunishment rate or not responding at all” (p 95). Filby and Appel (1966) presented an early example of this difficulty. Using a concurrent VI-VI reinforcement-punishment procedure that produced food and shock, Filby and Appel reported that little response suppression was observed at low shock intensities, but complete response suppression was observed at higher intensities. Moderate response suppression was not observed. Arbuckel and Lattal (1992) suggested that 
whereas FR or VR schedules of punishment delivery have consistent effects related to intensity and frequency of shock, shock presentation under VI schedules is less consistent. At some parameters of intensity or frequency of shock, there is an increase in response rate; at other levels, complete response suppression is observed.

The difficulty of maintaining consistent levels of responding was observed throughout the VI-titration procedure as well as in the FR-1 procedure during the choice phase of the experiment. It was hoped that the presentation of food immediately following the key peck would be adequate to maintain responding. The interaction between food presentation and shock delivery may have worked against the experimental goals, however, maintaining more responding on the key correlated with the three shocks than on the key correlated with the single shock.

In addition to the problem of maintaining responses, it is also theoretically necessary to verify that the stimulus, which is initially moderately aversive, remains so. Azrin (1960) reports that an increase in the intensity of a punisher has much the same effects as the initial introduction of the punisher; that is, there is a temporary decrease in response rates, but rates may approach pre-punished levels after some period of time. Thus, if a moderately aversive shock intensity and duration was identified, it would be necessary to periodically reassess its suppressive effects in the context in which it was first determined. This gradual change of punishing efficacy could account for the changes in behavior for the subjects that did experience the increasing sequence of delays to the three shocks. When the three shocks were presented at increasing delays, response patterns became sufficiently disorganized following several sessions that the long-term effects of repeating the choice procedure with the same shock intensity and changing delays to shock presentation were not fully examined. 
Future directions. A major obstacle to conducting this type of work is the maintenance of responding. In the present study, this was initially done using a VI schedule of food presentation followed by shock delivery. Given the difficulties of working with VI schedules of punishment (such as all-or-none patterns of responding) it is possible that a VI schedule was not the best to use. If a ratio schedule had been used, for example, response rates and latencies to responding could be considered as dependent variables indicative of moderate response suppression. In this preparation, food and shock could be scheduled independently (as in Filby and Appel's study). The independence of scheduling would also have the benefit of eliminating food-shock contiguity and, therefore, the interaction between the two stimuli. A potential difficulty with using a ratio schedule, however, would be the necessity to equate reinforcer and shock frequency across the schedules. If this detail could be resolved, the comparison between a smaller, more immediate aversive stimulus could have been compared to the presentation of a larger, delayed aversive stimulus.

Another way in which responding could be maintained while comparing a smaller, more immediate aversive stimulus to a larger, delayed aversive stimulus would be the use of probabilistic shock instead of shock perfectly correlated with the responding. The presentation of shock following a response with a probability of less than 1.0 would lead to responding that is more resistant to punishment. Arbuckel and Lattal (1992) suggested that lower shock probability per response results in a less behavioral suppression. Thus, decreasing the likelihood that a shock would occur following every response may circumvent the problem of response suppression. Instead of a choice between a single shock and three shocks, a more-probable shock could be presented in a choice situation with a less-probable shock. Delays to each could be manipulated following stable responding in baseline conditions. In this way, the same question of a choice 
between aversive events could be examined through the use of probabilistic shock as has been done with food (cf. Adriani \& Laviola, 2006).

Additionally, other aversive events, such as timeout from reinforcer presentation, could be used to assess choice between aversive events. As long as the event is moderately aversive (such that responding is maintained at moderate levels in the presence of the stimulus but suppressed relative to baseline), the presentation of a single event (or smaller amount of the event) could be compared in a choice presentation with multiple events (or a larger amount of the event). Thus, it is not imperative the shock is used in this procedure to assess choice between aversive events. The important difference would be that one event is differentially aversive from the alternative event.

Another alternative for a future study would be a more direct replication of Deluty's work. Instead of using the Evenden and Ryan (1996) procedure to generate delay-discounting functions within an experimental session, it would be possible to use a concurrent-chains schedule with pigeons and adjust delays between sessions. The use of concurrent chains may allow a more sensitive analysis of behavior. That is, in the discrete-trial method employed in this study, one response in each block would account for one-sixth (or, approximately 17\%) of the responses in that block. Increasing the number of possible responses (which would be limited in a free-operant arrangement only by the maximal rate of responding in which a subject can engage) would generate more sensitive measures of choice.

Although the logical foundation of this procedure seemed sound, methodological problems made it difficult to conduct. The use of a procedure that was structurally similar to previous delay-discounting research did not guarantee that the aversive events would function in a parallel way as with food. Perhaps an increase in the number of shocks presented would make 
this difference more salient and would, therefore, better control behavior. Alternatively, if the shocks were functioning as a conditioned reinforcer, this procedural change would not result in behavioral change. This is an empirical question, the answer to which may clarify the role the shocks are playing in the present experiment. If methods were devised to generate differential preference for one aversive event over another (as in the case of Deluty’s work) it would be possible to continue with this line of inquiry. 


\section{References}

Adriani, W. \& Laviola, G. (2006) Delay aversion but preference for large and rare rewards in two choice tasks: implications for the measurement of self-control parameters. $B M C$ Neuroscience, 7, 52.

Ainslie, G. W. (1974). Impulse control in pigeons. Journal of the Experimental Analysis of Behavior, 21, 485-489.

Arbuckel, J. L. \& Lattal, K. A. (1992). Molecular contingencies in schedules of intermittent punishment. Journal of the Experimental Analysis of Behavior, 58, 361-375.

Azrin, N. H. (1959). A technique for delivering shock to pigeons. Journal of the Experimental Analysis of Behavior, 2, 161-163.

Azrin, N. H. (1960). Effects of punishment intensity during variable-interval reinforcement. Journal of the Experimental Analysis of Behavior, 3, 123-142.

Baron, A., Kaufman, A., \& Fazzini, D. (1969). Density and delay of punishment of free-operant avoidance. Journal of the Experimental Analysis of Behavior, 12, 1029-1037.

Bertilson, H. S. \& Dengerink, H. A. (1975). The effects of active choice, shock duration, shock experience, and probability on the choice between immediate and delayed shock. Journal of Research in Personality, 9, 97-112.

Brown, P. L., \& Jenkins, H. M. (1968). Auto-shaping of the pigeon's key-peck. Journal of the Experimental Analysis of Behavior, 11, 1-8.

Cairns, G. \& Perkins, C. (1972). Delay of punishment and choice behavior in the rat. Journal of Comparative and Physiological Psychology, 79, 438-442.

Deluty, M. Z. (1978). Self-control and impulsiveness involving aversive events. Journal of Experimental Psychology: Animal Behavior Processes, 4, 250-266. 
Dinsmoor, J. A. (1954). Punishment I: The avoidance hypothesis. Psychological Review, 76, 4969.

Evenden \& Ryan (1996). The pharmacology of impulsive behaviour in rats: the effects of drugs on response choice with varying delays of reinforcement. Psychopharmacology, 128, 161-170.

Filby, Y. \& Appel, J. B. (1966). Variable-interval punishment during variable-interval reinforcement. Journal of the Experimental Analysis of Behavior, 9, 521-527.

Green, L., Fristoe, N., \& Myerson, J. (1994). Temporal discounting and preference reversals in choice between delayed outcomes. Psychological Bulletin Review, 1, 383-389.

Green, L. \& Myerson, J. (2004). A discounting framework for choice with delayed and probabilistic rewards. Psychological Bulletin, 130, 769-792.

Hake, D. F., Azrin, N. H., \& Oxford, R. The effects of punishment intensity on squirrel monkeys. Journal of the Experimental Analysis of Behavior, 10, 95-107.

Lerman, D. C., \& Vorndran, C. M. (2002). On the status of knowledge for using punishment: Implications for treating behavior disorders. Journal of Applied Behavior Analysis, 35, 431-464.

Mazur, J. E. (1987). In Commons, M., Mazur, J., Nevin, J., \& Rachlin, H. (Eds.) Quantitative Analyses of Behavior: The effects of delay and of intervening events on reinforcement value (pp. 55-73). Hillside, NJ: Lawrence Erlbaum Associates, Publishers.

Mazur, J. E. (1998). Choice with delayed and probabilistic reinforcers: effects of prereinforcer and postreinforcer stimulus. Journal of the Experimental Analysis of Behavior, 70, 253265.

Myerson, J. \& Green, L. (1995). Discounting of delayed rewards: models of individual choice. 
Journal of the Experimental Analysis of Behavior, 64, 263-276.

Rodriguez, W. A. \& Logan, F. A. (1980). Preference for punishment of the instrumental or the consummatory response. Animal Learning \& Behavior, 8, 116-119.

Skinner, B.F. (1953/1965). Science and Human Behavior. New York, NY: The Free Press. 
Curriculum Vitae

\title{
James W. Diller
}

Personal Information

Updated: December, 2006

School Address:

\author{
West Virginia University \\ Department of Psychology \\ 53 Campus Drive \\ Morgantown, WV 26506 \\ Ph: (304) 293-2001
}

E-mail:_ James.Diller@mail.wvu.edu

\section{Education}

August, 2004 -

present

Behavior Analysis Doctoral Training Program

Department of Psychology

West Virginia University, Morgantown, WV

August, 2001 -

Advisor: Karen G. Anderson, Ph. D.

May, 2004 Bachelor of Arts, Summa Cum Laude

McDaniel College, Westminster, MD

Major: Psychology

Minors: Philosophy \& Spanish

Undergraduate Honors Thesis: Timing of gap situations in pigeons

Advisor: Margaret McDevitt, Ph. D.

\section{Awards and Honors}

2004

Meltzer award in Psychology, McDaniel College

2002

Psi Chi Inductee

\section{Professional Affiliations}

Association for Behavior Analysis

Southeastern Association for Behavior Analysis

Maryland Association for Behavior Analysis 


\section{Teaching Experience}

Fall, 2006

October, 2006

Spring, 2006

Fall, 2005

November, 2005

Spring, 2005

April, 2005

Fall, 2004
Psychology 202, Research Methods, Lab Instructor; Enrollment: 20; Supervisor: Dr. Constance Toffle

Guest lecture, Learning and Memory, Marietta College, Marietta, OH. Topic: Behavior Analysis: Research \& Applications. Contact: Dr. Jennifer McCabe.

Psychology 101, West Virginia University; Lead Graduate Teaching Assistant; Enrollment: approximately 1,700 ; Supervisor: Dr. Cheryl McNeil

Psychology 101, West Virginia University; Lead Graduate Teaching Assistant; Enrollment: approximately 2,400; Supervisor: Dr. Cheryl McNeil

Guest Lecture, Physiological Psychology, West Virginia University; Topic: Schizophrenia; Supervisor: Dr. Karen G. Anderson

Psychology 101, West Virginia University; Enrollment: 117; Supervisor: Dr. Cheryl McNeil

Guest lecture, Physiological Psychology; Topic: Biological Bases of Learning \& Memory; Supervisor: Dr. Karen G. Anderson

Psychology 101, West Virginia University; Enrollment: 117; Supervisor: Dr. Jennifer Margrett

\section{Research Interests}

Behavioral pharmacology

Choice

Punishment

Basic operant research

\section{Relevant Skills}

Appropriate handling of rats as experimental subjects (2.5 years experience) Appropriate handling of pigeons as experimental subjects (5 years experience) Injections (rats): intraparatoneal (i.p.), subcutaneous (s.c.)

Programming: MedState Notation

\section{Research Projects}

Diller, J. W., Saunders, B. T. \& Anderson, K. G. Effects of acute and repeated administration of caffeine on delay discounting in rats. Manuscript in preparation.

Diller, J. W. \& Anderson, K. G. Development of an animal model of choice between aversive events. 
Summary: Masters thesis project; presenting pigeons with a choice between a single, immediate shock and three delayed shocks in order to develop an animal model of choice between aversive events.

Anderson, K. G. \& Diller, J. W. (In Preparation) Effects of learning history on impulsive responding. Summary: Examining effects of an extensive reinforcement history on "impulsive" choice in rats.

\section{Professional Presentations}

Diller, J. W., Saunders, B. T., \& Anderson, K. G. (2007). Effects of acute and chronic administration of caffeine on delay discounting in rats. Poster accepted for presentation at the annual meeting of the Association for Behavior Analysis. San Diego, CA.

Diller, J. W. \& Anderson, K. G. (2006). Effects of varying delay context on delay discounting in rats. Symposium presentation at the annual meeting of the Maryland Association for Behavior Analysis. Baltimore, MD.

Diller, J. W. \& Anderson, K. G. (2006). Choice between a single shock and three shocks in a discrete-trial procedure: Not what you might expect. Poster presented at the annual meeting of the Southeastern Association for Behavior Analysis. Greenville, SC.

Diller, J. W. \& Anderson, K. G. (2006). A parametric analysis of response-dependent shock intensity \& duration on food-maintained responding in pigeons. Poster presented at the annual meeting of the Association for Behavior Analysis. Atlanta, GA.

Diller, J. W. \& Anderson, K. G. (2005). Effects of reinforcement history on impulsive choice. Poster presented at the annual meeting of the Southeastern Association for Behavior Analysis. Wilmington, NC.

Diller, J. W. \& Anderson, K. G. (2005) Impulsive choice increases as a result of repeated exposure to a selfcontrol/ impulsivity choice paradigm. Poster to be presented at the annual meeting of the Maryland Association for Behavior Analysis. Baltimore, MD.

\section{Professional Service}

2005-2006 Student Representative, Maryland Association for Behavior Analysis. 